\title{
Las culturas del neolítico y calcolítico en Andalucía Occidental
}

\author{
Pilar Acosta Martínez *
}

\section{PRENOTANDO}

Este trabajo se inició en 1986 dentro de un ambicioso proyecto de un "Atlas del neolítico en Europa», dirigido por el profesor M. Otte de la Universidad de Lieja (Bélgica). Por razones, quizás de tipo financiero, tres años después, la dirección fue traspasada al profesor J. Guilaine del C.N.R.S. francés. Ante las anomalías existentes de cambios de esquemas y dilatación de la publicación por ese organismo, hemos considerado conveniente su aparición en la revista «Espacio, Tiempo y Forma», de la UNED.

El esquema seguido es el primitivamente propuesto para el Atlas de prehistoria europea, y no lo hemos variado para no vernos en la necesidd de rehacerlo, según otros criterios donde podrían haberse incluido algunos aspectos económicos y sociales, así como los referentes a la emergencia y el proceso del cambio cultural.

El enfoque del texto mira directamente hacia la objetiva presentación de la innovación tecnológica o de la evidencia arqueológica, como base y fundamento de posibles y posteriores explicaciones de los sistemas culturales, siempre subjetivas e hipotéticas.

Se ha puesto especial énfasis en las descripciones tipológicas del registro arqueológico, por lo que respecta a estructuras del hábitat y del enterramiento, de los artefactos, como la cerámica, la industria lítica y ósea, la metalúrgica y adornos, y de los escofactos, como elementos esenciales para desentrañar la economía.

* Catedrática de Prehistoria. Universidad de Sevilla. 
La escala de los sistemas ha sido simplemente esbozada, considerando las regiones y la extensión geográfica en que se integran los sistemas, la nomenclatura de los mismos, sus facies regionales y los principales yacimientos conocidos dentro de cada sistema, cuya distribución se expone en cinco mapas correspondientes a cada horizonte cultural tratado.

En determinados casos se han contemplado las estratigrafías de los yacimientos, para identificar y delimitar los estadios culturales de los sistemas, utilizando igualmente las fechas radiocarbónicas, calibradas o sin calibrar, expuestas en cinco tablas relativas a cada horizonte.

No dudamos de la problemática que representa el establecimiento y delimitación de horizontes culturales, estadios, períodos, fases, pero esta operación, aunque tenga mucho de subjetivo, es de gran utilidad y ayuda para entendernos y para poder estructurar en el tiempo las culturas de nuestra prehistoria.

Existe una serie de aspectos, modelos, factores o variantes en los que apenas se ha profundizado, por no entrar en la meta de este trabajo, donde predomina la objetividad. Estos aspectos podrían ser el ecosistema, la complejidad social, la escala demográfica, la interacción económica y la integración político-económica, simplemente esbozadas al tratar de la economía.

Por otra parte, se ha prescindido de las peligrosas hipótesis de una metodología deductiva y de las explicaciones dogmáticas del proceso de cambio o de la emergencia cultural, tan esenciales en la arqueología procesual.

En suma, esta sintesis sobre el neolitico y calcolítico de Andalucía Occidental, con todas sus omisiones, no pretende ser exhaustiva y completa, sino solamente servir de ayuda, como una visión panorámica de una pequeña parte de la arqueología material de Andalucía.

\section{NEOLITICO ANTIGUO}

\section{Región considerada}

Andalucía occidental podría dividirse teóricamente en sus cuatro provincias actuales, Huelva, Sevilla, Córdoba y Cádiz, pero, atendiendo a la geografía, más acorde con las comarcas culturales, podría dividirse en seis zonas: A) La Sierra Morena, al norte del Guadalquivir, entre Cortegana (Huelva) y Cardeña (Córdoba). B) El bajo y medio valle del Guadalquivir, desde Sanlúcar de Barrameda (Cádiz) hasta Montoro (Córdoba), con extensiones por los valles del Corbones y Genil. C) La campiña, al sur del Guadalquivir, desde Montellano (Sevilla) hasta 
Baena (Córdoba). D) El sur de Huelva, con las bajas cuencas del Guadiana, Odiel y Tinto. E) Las Sierras Subbéticas occidentales, desde Alcalá de los Gazules (Cádiz) hasta Archidona (Málaga). F) La costa mediterránea, desde Algeciras (Cádiz) hasta el Río Vélez (figura 1).

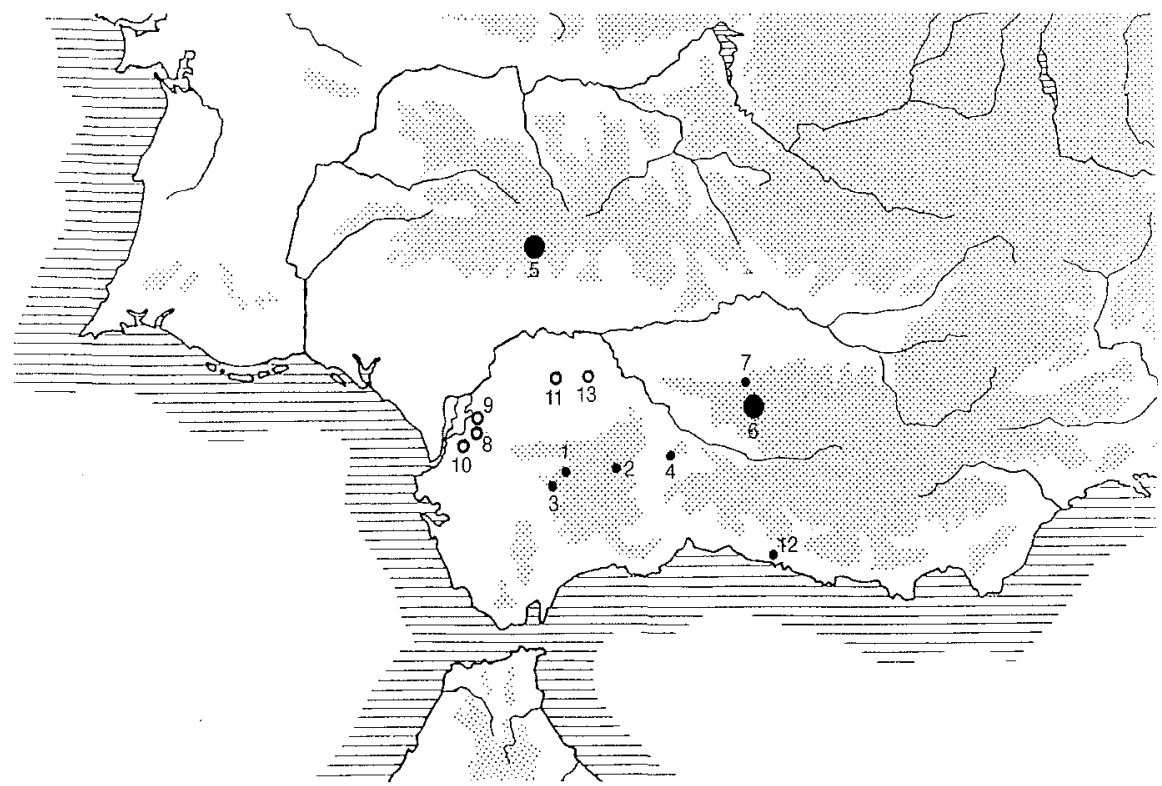

Fig. 1. Neolítico Antiguo ( $v$ l milenio - Primera mitad del $v$ milenio)

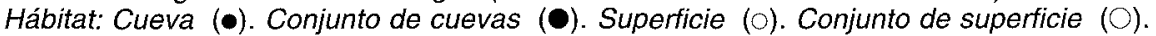

1. Cueva de la Dehesilla (Algar, Cádiz). 2. Cueva de la Pileta (Benaoján, Ronda, Málaga). 3. Cueva del Parralejo (San José del Valle, Cádiz). 4. Cueva de las Goteras (Mollina, Málaga). 5. Cuevas de Santiago (Cazalla de la Sierra, Sevilla). 6. Cuevas de Priego de Córdoba: Mármoles, Tocino, Inocentes, Negra, Murcielaguina. 7. Cueva de los Murciélagos (Zuheros, Córdoba). 8. El Cabezo (Lebrija, Sevilla). 9. Los Pozos (Lebrija, Sevilla). 10. Bustos (Trubujena, Cádiz). 11. Las Barrancas (Carmona, Sevilla). 12. Cueva de Nerja (Málaga). 13. Los Álamos (Fuentes de Andalucía, Sevilla).

Nombre de la cultura

Prescindiendo de la antigua nomenclatura de cultura de las cuevas de P. Bosch, neolítico hispano-mauritano de J. Martínez Santa Olalla y Neolítico I de J. San Valero, el neolítico antiguo de Andalucía occidental podría llarmase neolítico antiguo de la cerámica a la almagra, ya que el horizonte de la cerámica cardial no tiene aquí entidad. 


\section{Datación}

Tres yacimientos con estratigrafía, cuyos niveles inferiores surgen «ex novo" sin indicios de epipaleolítico, han proporcionado las fechas radiocarbónicas calibradas más altas del neolítico peninsular: La cueva de la Dehesilla (6300 - 5590 - 5545, 5075 - 4565 A.C.), la cueva Chica de Santiago (5460 - 5190, 5325 - 4910) y la cueva de los Murciélagos de Zuheros (entre el 5330 y 4570 A.C.), lo cual constata la aparición del neolítico en Andalucía occidental a finales del vII milenio a.C. o en la primera mitad del vı a.C.

\section{NEOLÍTICO ANTIGUO}

\begin{tabular}{|c|c|c|c|}
\hline YACIMIENTOS & LABORATORIOS & FECHAS B. P. & CALIBRACIÓN B. C. \\
\hline $\begin{array}{l}\text { C. Santiago Chica (Cazalla de la Sierra, } \\
\text { Sevilla) } 76 / 13\end{array}$ & Gak 8952 & $7890 \pm 180$ & \\
\hline C. Dehesilla (Algar, Cádiz) 77/11-10 & Gak 8953 & $7670 \pm 400$ & \\
\hline " $\quad$ " $\quad 77 / 8$ & Gak 8957 & $7440 \pm 160$ & \\
\hline $\begin{array}{l}\text { C. Santiago Chica (Cazalla de la Sierra, } \\
\text { Sevilla) } 76 / 12\end{array}$ & Gak 8947 & $7240 \pm 230$ & \\
\hline C. Dehesilla (Algar, Cádiz) 77/10 & $\begin{array}{l}\text { Gak } 8954 \\
\text { Gak } 8955\end{array}$ & $\begin{array}{l}7120 \pm 200 \\
7040 \pm 170\end{array}$ & $\begin{array}{l}6300-5590 \\
6150-5545\end{array}$ \\
\hline $\begin{array}{l}\text { C. Santiago Chica (Cazalla de la Sierra, } \\
\text { Sevilla) } 76 / 11\end{array}$ & Gak 8949 & $6380 \pm 150$ & $5460-5190$ \\
\hline C. Murciélagos (Zuheros, Córdoba) 5 & GrN 6926 & $6295 \pm 45$ & $5330-5185$ \\
\hline C. Dehesilla (Algar, Cádiz) 81/13 & Ugra 259 & $6260 \pm 100$ & $5455-4960$ \\
\hline C. Mısrciélagos (Zuheros, Córdoba) 5 & GrN 6638 & $6250 \pm 35$ & $5295-5075$ \\
\hline $\begin{array}{lll}" & 4 & 4\end{array}$ & CSIC 55 & $6170 \pm 130$ & $5285-4935$ \\
\hline$"$ & $\mathrm{CSIC} 53$ & $6190 \pm 130$ & $5295-4950$ \\
\hline " " " " " & $\operatorname{CSIC~} 54$ & $6190 \pm 130$ & $5295-4950$ \\
\hline $\begin{array}{l}\text { C. Santiago Chica (Cazalla de la Sierra, } \\
\text { Sevilla) } 80 / 12\end{array}$ & Ugra 254 & $6160 \pm 100$ & $5325-4910$ \\
\hline C. Murciélagos (Zuheros, Córdoba) & GrN 6169 & $6150 \pm 45$ & $5245-4965$ \\
\hline $\begin{array}{lll}" & 4 & 4\end{array}$ & CSIC 58 & $6100 \pm 130$ & $5250-4900$ \\
\hline$"$ & GrN 6639 & $6025 \pm 45$ & $5105-4900$ \\
\hline 5 & CSIC 56 & $5960 \pm 130$ & $5100-4700$ \\
\hline 4 & CSIC 59 & $5930 \pm 130$ & $5080-4570$ \\
\hline$"$ " & $\operatorname{CSIC~} 57$ & $5980 \pm 130$ & $5195-4710$ \\
\hline C. Dehesilla (Algar, Cádiz) 77/9 & Gak 8956 & $5920 \pm 160$ & $5075-4565$ \\
\hline $\begin{array}{l}\text { C. Santiago Chica (Cazalla de la Sierra, } \\
\text { Sevilla) } 76 / 11\end{array}$ & Gak 8948 & $5520 \pm 120$ & $4450-4335$ \\
\hline
\end{tabular}

\section{Extensión geográfica}

Los yacimientos, conocidos en función de las zonas prospectadas, se sitúan fundamentalmente en las estribaciones occidentales de la Subbética 
gaditana (Dehesilla, Parralejo) con extensión por la Serranía de Ronda (Pileta, Gato) y costa malagueña occidental (Benálmádena, Torremolinos, Málaga), atravesando el Corbones y Genil hacia las sierras cordobesas de Cabra y Priego (Murciélagos, Mármoles). Desde esta zona nuclear esta facies se extiende hacia el norte y noroeste por la Sierra Morena cordobesa y sevillana (cueva Chica de Santiago) a través de la importante vía del Corbones (Los Alamos, las Barranqueras). Este neolítico antiguo occidental de la cerámica a la almagra se funde en Andalucía oriental con la corriente de la cerámica cardial de origen levantino (Carigüela), quizás a finales del vı milenio a.C.

\section{Cerámica}

La extraordinaria calidad de la cerámica se impone en rápida evolución, destacándose como especie característica, la almagra o de barniz rojo brillante, generalmente decorada con geometrismos de paralelas incisas o acanaladas y admitiendo otras técnicas como la impresión y la plástica. En la Dehesilla la mitad de la cerámica decorada del neolítico antiguo es de la especie almagra. La especie plástica o de relieves es normal en todos los yacimientos, ocupando en la Dehesilla el $12 \%$ de los tipos decorados y existiendo en menor proporción la impresa no cardial (3\%). La especie cardial, diferente a la posterior cardialoide ejecutada con matriz dentada es un elemento sumamente extraño y raramente presente en las sierras gaditanas y malagueñas, marisma (Bustos), campiña sevillana (Los Alamos) y Costa del Sol, estando ausente en Córdoba, Sierra Morena y Huelva.

Las formas más frecuentes son los cuencos profundos, semiesféricos, vasos ovides, hombros entrantes cóncavos, acompañadas de elementos de prehensión como asas de cinta, de apéndice superior, de codo, pitorro y mamelones variados (figura 2).

\section{Industria lítica}

La industria lítica tallada corresponde a la facies microlaminar de supervivencias epipaleolíticas con muy escaso componente geométrico, siendo tipos normales las láminas, laminitas, lascas y lasquitas, preparadas para raspadores, buriles, perforadores, láminas de dorso abatido, de retoque continuo, muescas, fracturas, etc.

La industria de piedra pulimentada está debilmente representada por azuelas, apareciendo las hachas al final de la fase. Los elementos de mo- 

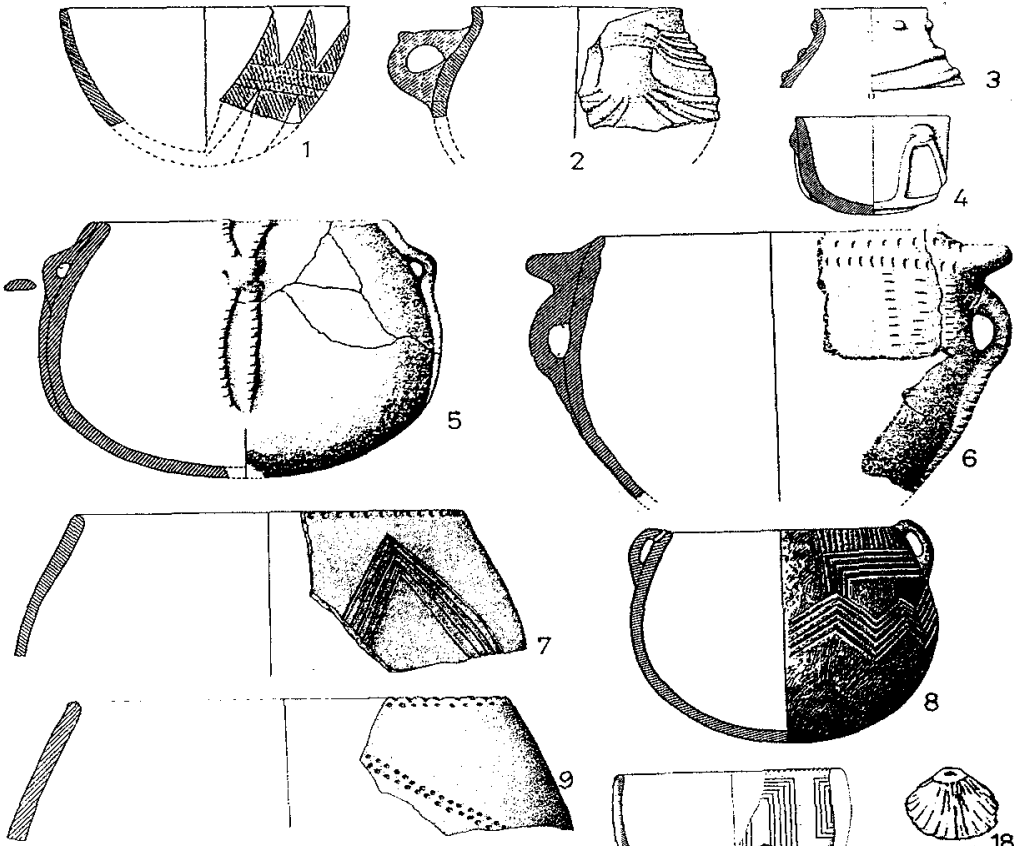

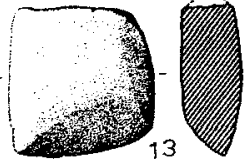

$16 \quad 0.17$
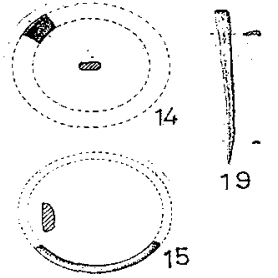

19
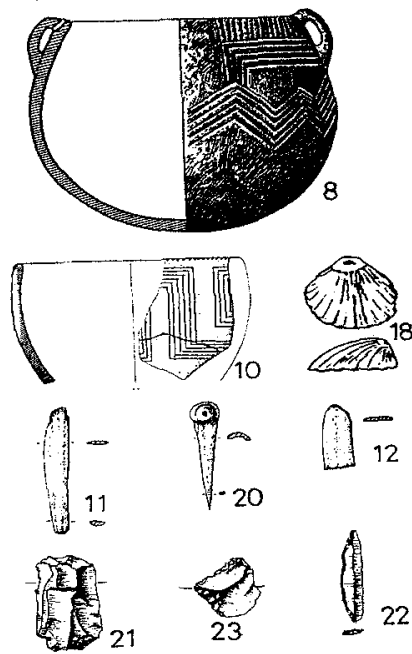

Fig. 2. Neolítico Antiguo.

1. Vaso semiesférico, decoración cardial e incisa. 2. Vaso globular, asa de cinta con apéndice, cordones. 3. Vaso globular con gollete, cordones, mamelones. 4. Cuenco cilíndrico, mamelones, cordones. 5 . Vaso ovoide, asas de túnel, cordones con impresiones, a la almagra. 6. Vaso ovoide asas de puente con apéndice, cordones e impresiones. 7. Vaso ovoide, a la almagra, decoración acanalada e impresa. 8. Vaso globular, asas de puente perforadas, decoración acanalada e impresa. 9. Vaso ovoide, a la almagra, decoración puntillada e impresa. 10. Vaso semi-ovoide, a la almagra, decoración acanalada. 11. Espátula-gradina de hueso. 12. Id. 13. Azuela de piedra pulimentada. 14. Brazalete de esquisto. 15. Brazalete de mármol. 16. Anillo de hueso. 17. Dentalium perforado. 18. Cardium perforado. 19. Aguja de hueso. 20. Punzón de metapodio de ovicáprido. 21. Lasca-raspador de silex. 22. Laminita-punta de borde abatido de silex. 23. Lasca denticulada de silex.

Procedencia:

1-2: Cueva del Parralejo (San José del Valle, Cádiz). 2, 3, 10, 12, 14-17, 19-23: Cueva de la Dehesilla (Algar, Cádiz). 5: Cueva de la Murcielaguina (Priego de Córdoba. 6: Cueva Cholones (Priego de Córdoba). 8: Cueva de los Murciélagos (Zuheros, Córdoba). 9: Cueva Chica de Santiago (Cazalla de la Sierra, Sevilla). 13 y 18: Cueva de los Mármoles (Priego de Córdoba). 1, 2, 7 y 8: según M. Pellicer 3, 4, 10-12, 14-17, 19-23: según P. Acosta y M. Pellicer. 9: según P. AcostA. 5, 6, 13 y 18: según $B$. GAVILÁN. 
lienda consisten en molinos planos y naviformes, moletas o cantos rodados, generalmente manchados de ocre.

\section{Industria ósea}

La industria del hueso, suficiente documentada en las cuevas de la Dehesilla, Santiago Chica, Murciélagos y otras, consiste en punzones de metápodos y huesos largos cortados, espátulas y puntas.

\section{Adornos}

El elemento más característico es el brazalete de calcita o mármol sin estrías, documentados en las estratigrafías de la Dehesilla y Santiago Chica, surgiendo al final del horizonte los tipos anchos estriados, según se infiere en la costa malagueña y en la cueva de los Murciélagos de Zuheros. Se inician igualmente los brazaletes de pizarra en forma de corona circular. Por su abundancia, variedad y alta cronología parece que su emergencia tendría lugar en la costa malagueña, desde donde se distribuirían hacia el interior. Otros elementos de adorno son las cuentas de piedra perforadas, las cuentas tubulares y anillos de hueso, los dientes perforados y especialmente las conchas marinas, muy abundantes en los yacimientos costeros.

\section{Economía}

Según los análisis de la fauna, en la Dehesilla la caza ocupa el $75 \%$ y los animales domésticos el $25 \%$, porcentajes muy similares a los de la cueva Chica de Santiago, donde la caza alcanza el $77 \%$ y los domésticos el $23 \%$. Entre las especies cazadas, por orden decreciente, en la Dehesilla tenemos el ciervo, conejo, uro, jabálí y lince y en Chica de Santiago el jabalí, ciervo y corzo. Las especies domésticas se distribuyen en la Dehesilla, en orden decreciente, el cerdo, ovicáprido y bóvido y en Chica de Santiago solamente el bóvido. En Murciélagos de Zuheros aparecen domesticados la oveja, el bóvido y la cabra.

La agricultura, ausente en la costa, sierras de Cádiz y Málaga y Sierra Morena, parece confirmarse en las sierras del sureste de Córdoba (Mármoles y Murciélagos), con la presencia de escanda, trigo común y cebada. Como alimentos de depredación son comunes las bellotas y olivas silvestres. 


\section{Ritos funerarios}

El enterramiento se practica en cueva, tanto sepulcral como de habitación. El hallazgo más importante se efectuó en la Dehesilla, donde se descubrieron varios enterramientos individuales y múltiples adultos e infantiles, en posición encogida y decúbito lateral, protegidos por piedras, con un ajuar de vasitos con ocre, laminitas de silex, fragmento de pectúnculo y caracoles, con indicios de cremación y algún cráneo pintado de ocre.

\section{Arte rupestre}

Aunque es arduo adscribir al neolítico antiguo representaciones ruprestres, parecen pertenecer a este momento algunos complejos del Campo de Gibraltar de tipo seminaturalista, así como ciertas pinturas animalísticas y antropomorfas de los abrigos del Tajo de las Figuras, Pretinas, Bacinete y Palomas.

\section{Hábitat}

El hábitat más común es la cueva, de aquí su antigua denominación, pero, conforme avanza la investigación, las prospecciones van registrando más yacimientos de superficie en zonas llanas, en los valles de Guadalquivir y sus afluentes, marismas y campiña. Por falta de investigaciones desconocemos la forma, tamaño y características internas de los poblados de superficie, puesto que sólo se han practicado sondeos estratigráficos en cuevas sevillanas, cordobesas y malagueñas y en el yacimiento de superficie del Cabezo de Lebrija. En Los Pozos (Lebrija) se han detectado cabañas circulares con zócalos de piedra.

\section{Yacimientos}

Se tienen documentados una veintena de yacimientos de los que el $75 \%$ son en cueva, distribuidos por la Sierra Subbética de Cádiz (Dehesilla, Parralejo, Palomas), de Sevilla (San Doroteo), del sur de Córdoba (Murciélagos, Mármoles, Tocino, Inocentes, Negra, Murcielaguina), de Málaga (Algarrobo, Gato, Pileta, Goteras), costa malagueña (Botijos, Tesoro, Hoyo de la Mina), Sierra Morena (Santiago Chica). 
Los yacimientos de superficie se extienden por la marisma (Cabezo de Lebrija, Bustos, Los Pozos) y por la campiña sevillana (Las Barrancas, Los Álamos), siendo muy difícil su adscripción a fases concretas por falta de excavaciones.

\section{Estadios}

Solamente en tres yacimientos en cueva han podido delimitarse fases en función de la cerámica, estratigrafía y C 14. En la cueva de la Dehesilla corresponderían a la fase $A$ los niveles 14-12 y a la fase $B$ los niveles 1110 del corte De-81. En el corte $B$ de la Cueva del Parralejo los niveles 11. 9 podrían considerarse de la fase A o inicial y el nivel 8 de la fase B. En el corte SCh-80 de la cueva Chica de Santiago, se atribuye a la primera fase el nivel 12 y a la segunda el 11. En la cueva de los Murciélagos de Zuheros y Cabezo de Lebrija resulta difícil determinar fases del neolítico antiguo por la uniformidad de su registro.

\section{Facies regionales}

Podrían delimitarse varias facies en función de la geografía y del registro arqueológico. En tal caso tendríamos la facies nuclear de las Sierras Subbéticas occidentales con extensiones por el este de Cádiz, oeste de Málaga y sureste de Córdoba, donde predomina la cerámica a la almagra decorada, la facies de la costa oriental de Cádiz y occidental de Málaga, también con cerámica a la almagra y muy débil presencia de cardial, la facies de la campiña sevillana con yacimientos de superficie portadores igualmente de cerámica a la almagra, la facies del bajo Guadalquivir y marismas con débil presencia de cerámica impresa y cardial y la facies de Sierra Morena con cerámica de relieves y a la almagra y ausencia de cardial, permaneciendo Huelva desconocida por falta de investigaciones.

\section{NEOLITICO MEDIO}

\section{Región considerada}

Se caracteriza por las mismas circunstancias observadas en el neolítico antiguo, relativas a las actuales provincias de Huelva, Sevilla, Córdoba, Cádiz y parte occidental de Málaga. 
Nombre de la cultura

Dada la evolución observada, a partir del neolítico antiguo, en el auge demográfico y en el registro arqueológico, podría denominarse también neolítico pleno, de apogeo de la cerámica a la almagra, según las zonas, y, muy especialmente, neolítico de la cerámica incisa, no siendo correcto el apelativo de epicardial por la insignificante entidad de esta especie cerámica en la fase anterior.

\section{Datación}

Por las fechas radiocarbónicas el neolítico medio ocuparía la segunda mitad del v milenio a. C y la primera mitad del IV. De la Cueva de la Dehesilla tenemos, sin calibrar, la fecha de $3970 \pm 170$ a. C. para los niveles $9 / 8$ del corte 1977. De la cueva Chica de Santiago disponemos de las fechas $4430 \pm 150$ y $3570 \pm 120$ a. C. para el nivel 11 de 1976 y la fecha calibrada 4450 - 4335 a. C. De la cueva de los Murciélagos de Zuheros, considerada anteriormente del neolítico antiguo y medio, tenemos la fecha sin calibrar de $4200 \pm 45$ a. C., del nivel 4 .

\section{NEOLÍTICO MEDIO}

\begin{tabular}{lcc}
\hline \multicolumn{1}{c}{ YACIMIENTOS } & LABORATORIOS & FECHAS B. P. \\
\hline C. Toro (Antequera, Málaga) & & $6400 \pm 280$ \\
C. Murciélagos (Zuheros, Córdoba) 4 & GrN 6640 & $6196 \pm 45$ \\
\hline
\end{tabular}

Extensión geográfica

Es evidente que en el neolítico medio se produce cierta eclosión demográfica, confirmada en las estratigrafías, con aumento del registro en cantidad y diversificación y por la emergencia y evolución de yacimientos en el ámbito geográfico. Por la evidencia arqueológica y por las cronologías absolutas parece plausibie creer que desde la zona nuclear de las Serranías de Cádiz y Ronda, Costa malagueña y sierras meridionales cordobesas el neolítico medio se expande por la Hoya de Antequera, bajo valle del Guadalquivir, Campiñas sevillana y cordobesa, sur de Huelva y Sierra Morena, multiplicándose los yacimientos de superficie por las zonas llanas y bajas (figura 3 ). 


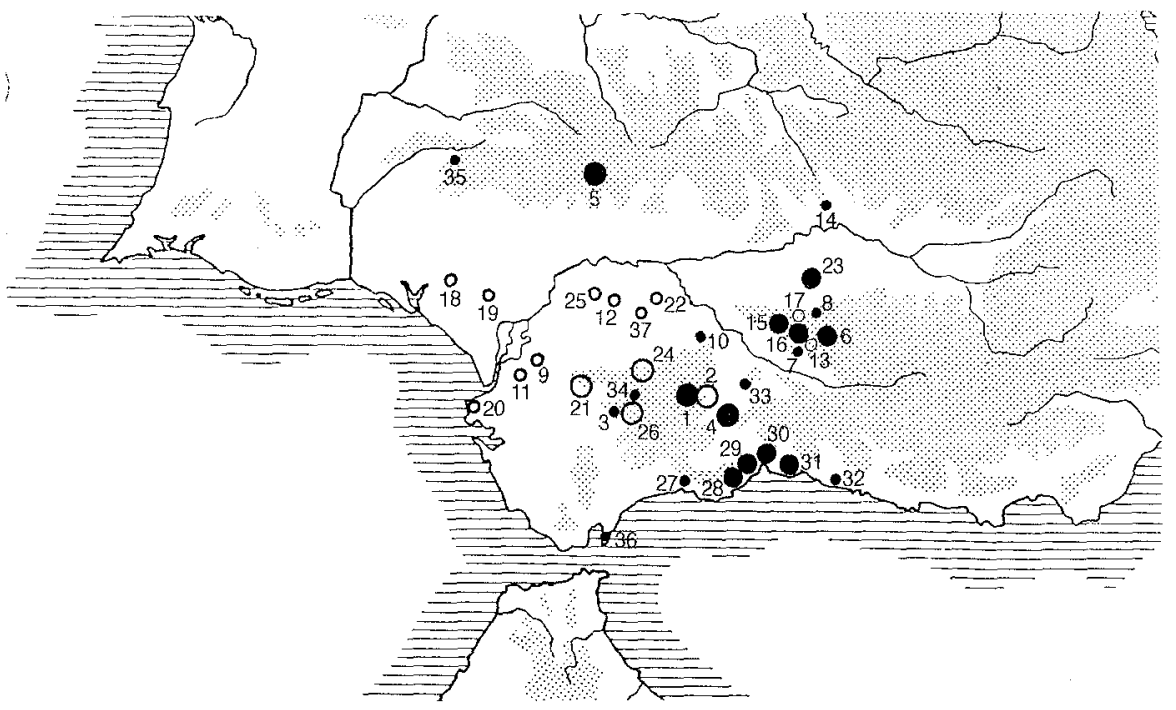

Fig. 3. Neolítico Medio (Segunda mitad del $v$ milenio - Primera mitad del iv milenio)

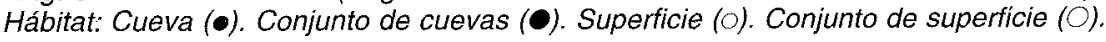

1. Cuevas de Ronda (Málaga): Gato, Alfaques, Chivos, Pileta. 2. Poblados de superficie de la depresión de Ronda (Málaga) (20). 3. Cueva del Parralejo (San José del Valle, Cádiz). 4. Cuevas de Alozaina (Málaga): Algarrobo, Sima Mesa. 5. Cuevas de Santiago (Cazalla de la Sierra, Sevilla). 6. Cuevas de Priego de Córdoba: Mármoles, Tocino, Mucielaguina, Cholones, Majá del Caldeıo, Huerta Anguita, Higuerón, Inocentes. 7. Cueva Negra (Rute, Córdoba). 8. Cueva de los Murciélagos (Zuheros, Córdoba). 9. El Cabezo (Lebrija, Sevilla). 10. Cueva de Marinaleda (Sevilla). 11. Bustos (Trebujena, Cádiz). 12. Las Barrancas (Carmona, Sevilla). 13. El Esparragal (Priego de Córdoba). 14. Cueva del Cañaveralejo (Adamuz, Córdoba). 15. Cuevas de Cabra (Córdoba): Puchero, Mina Jarcas. 16. Cuevas de Carcabuéy (Córdoba): Palanzuela, Gallinera, Muertos. 17. El Castillejo (Carcabuéy, Córdoba). 18. La Dehesa (Lucena del Puerto, Huelva). 19. El Judío (Almonte, Huelva). 20. Faro de Chipiona (Cádiz). 21. Arcos de la Frontera (Cádiz): El Yugo, Los Bermejales. 22. San Pedro (Fuentes de Andalucía, Sevilla). 23. Castro del Río (Córdoba): CR 87-12, San Joaquín II, Guta, CR-87-16, La Polonia, CR 87-3. 24. Cabezo Hortales (Prado del Rey, Cádiz). 25. Cortijo del Cerro II (Carmona, Sevilla). 26. San José del Valle (Cádiz): El Almendral, La Ventosilla, La Doncella. 27. Cueva Pecho Redondo (Marbella, Málaga). 28. Cuevas de Benalmádena (Málaga): Botijos, Zorrera, Sáhara. 29. Cuevas de Torremolinos (Málaga): Arroyo de la Miel, Carramolo, Encanto, Mármoles, Tapada, Tesoro. 30. Cuevas de Málaga: Belda, Piedras, San Marcos. 31. Cuevas de La Cala del Moral (Málaga): Cantera, Suizo, Hoyo de la Mina, Victoria. 32. Cueva de Nerja (Málaga). 33. Cueva de Doña Trinidad (Ardales, Málaga). 34. Cueva de la Dehesilla (Algar, Cádiz). 35. Cueva de la Mora (Jabugo, Huelva). 36. Cuevas de Gibraltar. 37. Los Álamos (Fuentes de Andalucía, Sevilla).

\section{Cerámica}

Aumenta el volumen de cerámica con diversificación de especies, tanto lisas como decoradas, con absoluto predominio de la incisa geométrica, 
que en la Dehesilla alcanza el $73 \%$ de la cerámica decorada, llegando a su apogeo la cerámica a la almagra fuera de la zona nuclear, donde decae considerablemente. La técnica incisa, muy abundante, decora los vasos con variados geometrismos rectilíneos y curvilíneos, combinándose con impresiones y puntillado, y persistiendo la incrustación de pasta roja. La técnica grabada o esgrafiada es frecuente y la cardialoide está presente.

Las formas cerámicas siguen la anterior evolución, conservándose los galbos semiesféricos, de cuencos profundos, ovoides y de tendencia globular, marcándose débiles carenas con hombros cóncavos. Los bordes comienzan a destacarse, siendo típicos los vasos globulares con gollete. Las asas se diversifican con todo tipo de mamelones y lengüetas, asas de cinta con apéndice en la parte superior, de codo, asas puente y túnel, multiforadas y de pitorro (figura 4).

\section{Industria lítica}

La industria lítica tallada sigue la trayectoria anterior de carácter microlaminar, con tipologías de láminas y lascas retocadas con función de raspadores, buriles, perforadores y raederas. Persisten las láminas con fracturas, dorsos, muescas y denticulados. Los geométricos son muy raros. Los pulimentados se presentan con más abundancia con formas de hachas, azuelas y cinceles. Los elementos de molienda como los molinos y moletas son más frecuentes que en la fase anterior.

\section{Industria ósea}

La industria del hueso se diversifica con el punzón-diente, aguja, punzón plano con ancha cabeza, punzón doble, matriz para decorar cerámica, anzuelo, enmangue, cincel, tubo, persistiendo en abundancia los punzones de metápodos, los de media caña y las espátulas.

\section{Adornos}

Es el momento del apogeo de los brazaletes de mármol anchos con estrías, cuyo origen parece radicar en la costa malagueña, desde donde se extienden intensamente hacia el macizo montañoso del sureste cordobés y débilmente hacia Granada, llegando hasta Almería (cueva de Ambrosio). Persisten los tipos de brazaletes estrechos sin estrías, acompañados por los de pizarra. También parecen proceder de la costa los 

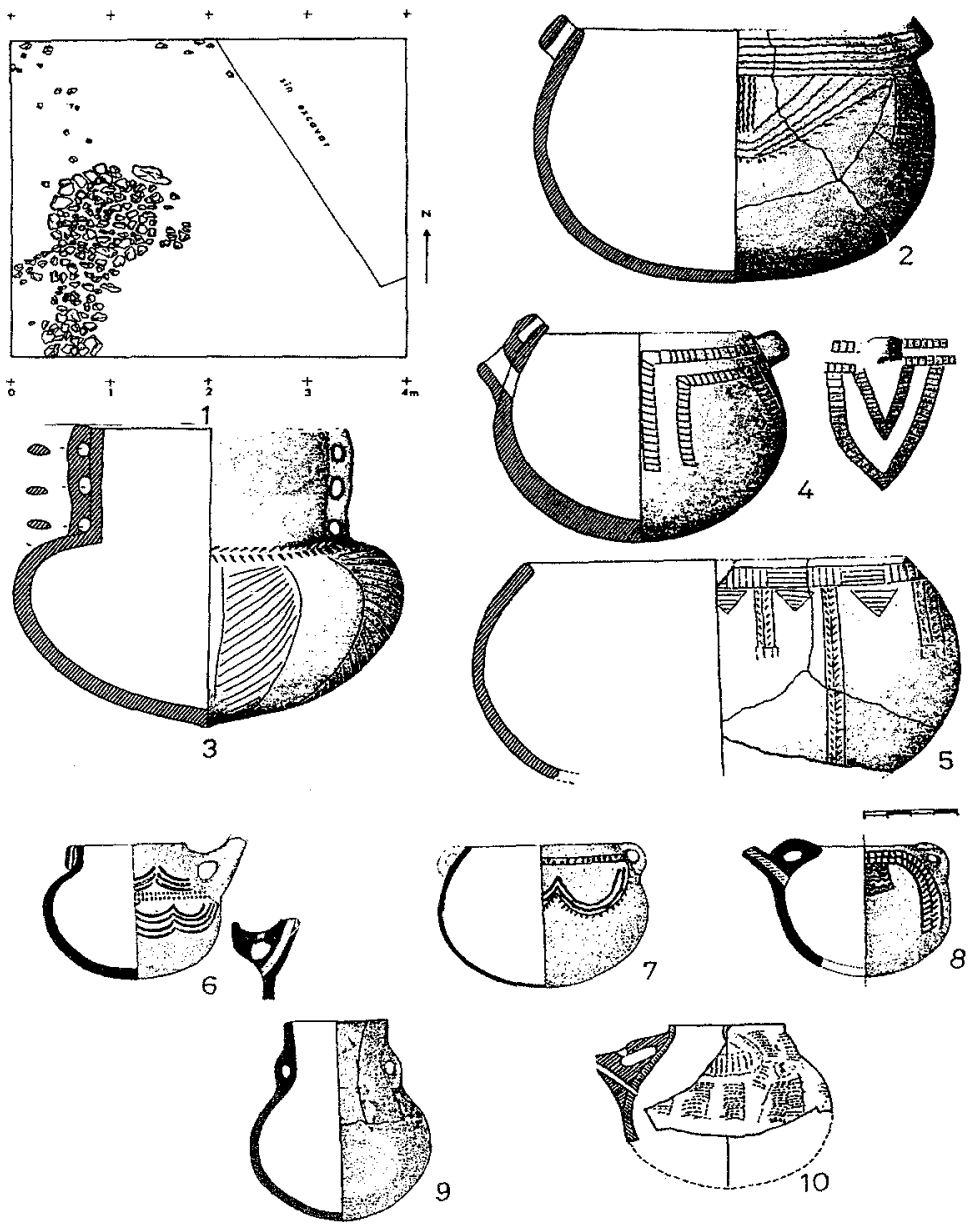

Fig. 4. Neolítico Medio.

1. Estructura turriforme de piedra. 2. Vaso globular, a la almagra, decoración impresa. 3. Vaso ovoide, con gollete y asas multiforadas, decoración incisa. 4. Vaso globular, a la almagra, asas de pitorro y túnel. 5. Vaso globular, a la almagra, decoración incisa. 6 . Vaso globular, a la almagra, asa de pitorro, decoración acanalada y puntillada. 7. Vaso globular, asas de puente, decoración acanalada y puntillada. 8. Vaso globular, a la almagra, asas de pitorro y puente, decoración acanalada e impresa. 9. Vaso globular con gollete y asas de puente. 10. Vaso globular con gollete, asa de pitorro, decoración cardialoide.

Procedencia:

1: El Cabezo (Lebrija, Sevilla). 2 y 4: Cueva de la Murcielaguina (Priego de Córdoba). 3 y 5: Cueva de los Mármoles (Priego de Córdoba). 6-9: Cueva de los Botijos (Benalmádena, Málaga). 10: Cueva de la Dehesilla (Algar, Cádiz).

1: según A. Caro, P. Acosta y J. L. Escacena. 2-5: según B. Gavilán. 6-9: según C. Olaria. 10: según P. Acosta y M. Pellicer. 
brazaletes de pectúnculo, que se inician en este momento, alcanzando el sur de Córdoba y Sierra Morena. Otros adornos frecuentes son las cuentas de collar discoidales de caliza, las conchas marinas perforadas, dientes perforados, tubitos, placas y anillos de hueso con o sin protuberancia (figura 5).

\section{Economía}

La agricultura cerealística parece generalizarse en el sur de Córdoba (Murciélagos, Mármoles) y norte de Málaga (cueva del Toro), para cuya molturación se dispone de molinos planos y naviformes y moletas. La principal dieta alimenticia parece ser la animal. En la Dehesilla la fauna doméstica, compuesta de ovicáprido $(28 \%)$, cerdo $(31 \%)$, bóvido $(18 \%)$, caballo $(1,5 \%)$ y perro $(1 \%)$, predomina sobre la caza $(14 \%)$, compuesta de ciervo $(8,5 \%)$, jabalí $(3,5 \%)$, conejo $(1,2 \%)$, zorro $(1 \%)$, liebre, lagarto y almejas de río.

En la cueva Chica de Santiago predomina la fauna salvaje con un $72 \%$, siendo los porcentajes, el ciervo $(27,31 \%)$, caballo $(19,24 \%)$, sus $(16,21 \%)$, ovicápridos $(13,04 \%)$, oso $(9,62 \%)$, bóvido $(8,46 \%)$, corzo $(3,17 \%)$, lobo $(1,44 \%)$, conejo $(0,67 \%)$, liebre $(0,57 \%)$, gato montés $(0,24 \%)$, milano $(0,07 \%)$ y galápago $(0,06 \%)$. En la cueva de los Murciélagos de Zuheros las especies de fauna en orden decreciente son conejo, oveja, jabalí, bóvido, cabra, liebre, zorro y ciervo y, como especies vegetales para la dieta, aparecen bellotas, pistachos y olivas.

\section{Ritos funerarios}

El enterramiento se practica en las mismas cuevas de habitación con inhumación individual, estando el cadáver encogido y protegido por piedras, sin detectarse ajuares, solamente con ocre y caracoles (Dehesilla). En otros casos, se entierra en simas, grietas y galerías estrechas (Hoyo de la Mina, Tesoro, simas de Benaocaz) con ajuares de vasos. Es frecuente la aparición, en las cuevas de habitación, de restos humanos dispersos.

\section{Arte rupestre}

Iniciado anteriormente, este arte, plasmado en las paredes rocosas de los abrigos, se afianza con esquematismos pintados en rojo o negro y con 

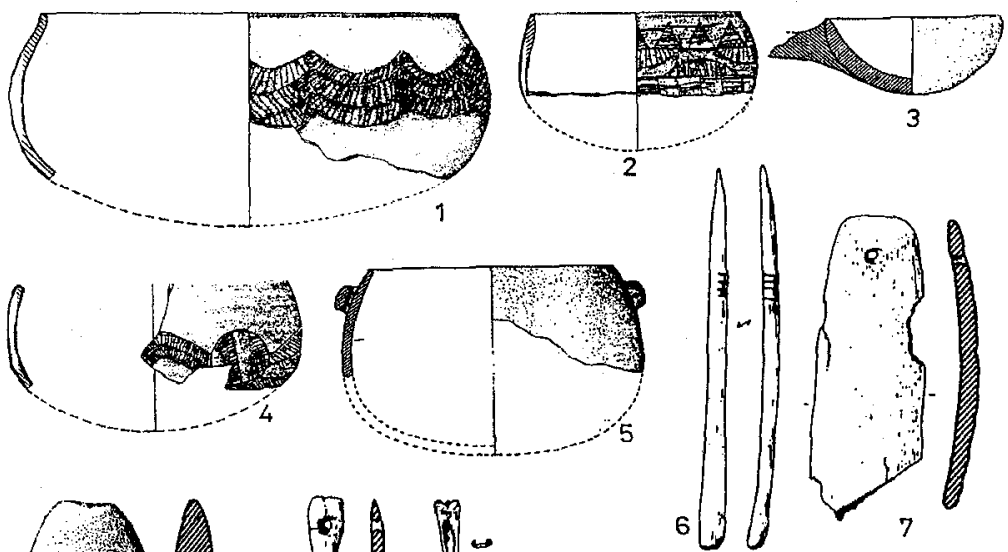

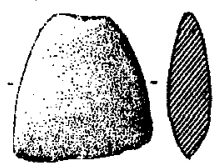

8

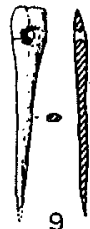

9

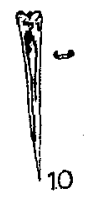

$\underbrace{g}_{13}$
18

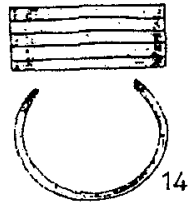

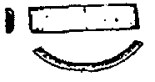

15<smiles>CCCCCCCCCCCC</smiles>

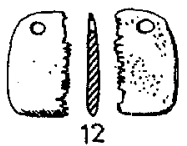

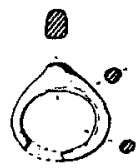

16

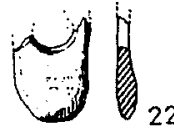

22<smiles>C1=C[C@H]2CC[C@H]1O2</smiles>

(C) 89 18

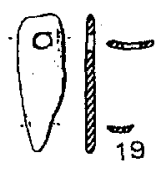

19

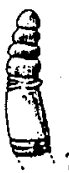

20

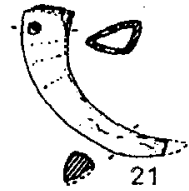

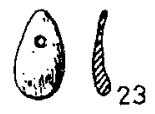
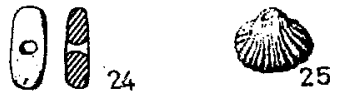

Fig. 5. Neolítico Medio.

1. Vaso semiesférico, bruñido, decoración incisa. 2. Id. 3. Cuenco con mango. 4. Vaso semiesférico, bruñido, decoración incisa. 5. Vaso semiesférico, asas de túnel verticales. 6. Aguja de hueso, decoración grabada. 7. Espátula de hueso. 8. Hachita pulimentada. 9. Aguja de hueso con ojo. 10. Punzón de metapodio de ovicáprido. 11. Placa-gradina de hueso. 12. Id. 13. Anzuelo de hueso. 14. Brazalete de mármol con estrías. 15. Brazalete de mármol liso. 16. Anillo de hueso con protuberancia. 17. Tubito de hueso. 18. Cuentas discoidales de caliza. 19. Colgante de hueso. 20. Colgante segmentado de piedra. 21. Colmillo de jabalí perforado. 22. Colgante de hueso. 23. Diente perforado. 24. Colgante de piedra. 25. Cardium perforado. Procedencia:

1-4: Cueva de la Dehesilla (Algar, Cádiz). 5: Cueva Chica de Santiago (Cazalla de la Sierra, Sevilla). 6-8, 16-18, 21: Cueva de los Mármoles (Priego de Córdoba). 9, 12, 13, 19, 20, 22 25: Cueva de la Murcielaguina (Priego de Córdoba). 10, 11, 14 y 15: Cueva de los Murciélagos (Zuheros, Córdoba).

1-4: según P. Acosta y M. Pellicer. 5: según P. Acosta. 6-9, 12, 13, 16-25: según $B$. GAVILÁN. 10, 11, 14 y 15: según A. M. VICENT y A. M. MuÑoz. 
una temática de zoomorfos, ramiformes, zig-zags y geometrismos diversos, análogos a los representados en cerámicas y objetos muebles del neolítico medio (Murcielaguina, Mármoles, Nerja), situándose el foco de este arte en las sierras de Tarifa.

\section{Hábitat}

El hábitat en cueva prosigue en los macizos calizos, generalizándose el asentamiento de superficie en los valles fluviales (Corbones, Guadajoz), marismas (Judío, La Dehesa), y altas depresiones (Ronda, San José del Valle). Según los datos disponibles, más del $50 \%$ de los yacimientos son ya de superficie.

\section{Yacimientos}

Las cuevas de los macizos montañosos de Cádiz (Dehesilla, Parralejo, Palomas, Picado), del occidente malagueño (Toro, Gato, Pileta, Algarrobo, Benalmádena, Torremolinos, Málaga), del macizo suroriental de Córdoba y Sierra Morena occidental (Mora, Santiago), prosiguen habitadas o se inicia la habitación, mientras los poblados de superficie se van imponiendo en las vías fluviales, depresiones fértiles y zonas endorréicas. En la depresión de Ronda se enumeran más de una veintena de poblados. Igualmente sucede en el valle medio del Guadajoz, donde se localiza una decena. En las marismas de Huelva se documentan El Judío y La Dehesa y en las de Sevilla, Bustos y el Cabezo de Lebrija. En el Corbones se hallan Las Barrancas, El Cerro y Los Álamos. En Cádiz se han descubierto varios conjuntos en Arcos de la Frontera (Yugo, los Bermejales), Prado del Rey (los Hortales), Chipiona y San José del Valle (Almendral, Ventosilla, Doncelia).

\section{Estadios}

Tres son las cuevas que, según sus estratigrafías, pueden definir estadios del neolítico medio. En el corte 1981 de la Dehesilla los niveles 9-8 corresponderían a la fase A y los niveles 7-6 a la B. En la cueva del Parralejo los niveles 8-7 serian del neolítico medio A y los 6-5 del B. En el corte 1980 de Chica de Santiago el nivel 10 pertenecería a la fase A y el 9 a la fase $B$. 
Facies regionales

Las consideraciones vertidas en el apartado "Región considerada» pueden aplicarse a la caracterización de las facies, distinguiéndose las de Sierra Morena, Valle medio y bajo del Guadalquivir, alta campiña, sureste de Huelva, sierras Subbéticas occidentales y costa malagueña.

\section{NEOLITICO FINAL}

\section{Región considerada}

Provincias de Huelva, Sevilla, Córdoba, Cádiz y parte occidental de Málaga con los accidentes geográficos de Sierra Morena, Valle del Guadalquivir, depresión meridional de Huelva, Sierras Subbéticas y costa malagueña.

\section{Nombre de la cultura}

Ante la aparición de ciertos elementos típicos del calcolítico, como los silos y los platos carenados, el neolítico final puede considerarse como un neolítico de transición, también denominado neolítico de los silos o neolítico reciente y de la cerámica lisa.

\section{Datación}

Las fechas obtenidas en la fase inicial de Papauvas I de finales del IV milenio, en el extenso poblado de La Viña (Rota), repleto de silos (3480 \pm 60 y $3130 \pm 90$ a. C.) y en el nivel 5 del corte 1976 de la cueva Chica de Santiago (3150 \pm 120 a. C.), el neolítico final de Andalucía occidental podría fecharse entre el 3500 y el 2800 a. C., independientemente de ciertas oscilaciones más o menos intensas de facies retardatarias.

\section{NEOLÍTICO FINAL}

\begin{tabular}{lcc}
\hline \multicolumn{1}{c}{ YACIMIENTOS } & LABORATORIOS & FECHAS B. P. \\
\hline C. Toro (Antequera, Málaga) III & & $5450 \pm 120$ \\
La Viña (Rota, Cádiz) & Ugra 730 & $5430 \pm 60$ \\
C. Toro (Antequera, Málaga) III & & $5320 \pm 230$ \\
C. Santiago Chica (Cazalla de la Sierra, Sevilla) 76/5 & Gak 8950 & $5100 \pm 120$ \\
La Viña (Rota, Cádiz) & Ugra 362 & $5080 \pm 60$ \\
\hline
\end{tabular}




\section{Extensión geográfica}

La población prosigue la ocupación de los anteriores yacimientos, surgiendo en las depresiones y zonas bajas nuevos establecimientos de superficie, como el Papauvas (Huelva), costa gaditana (Rota, Puerto de Santa María, Barbate), campiña sevillana (Carmona, El Coronil), Guadalquivir medio (Castro del Río) y depresiones de Ronda y Antequera (figura 6).

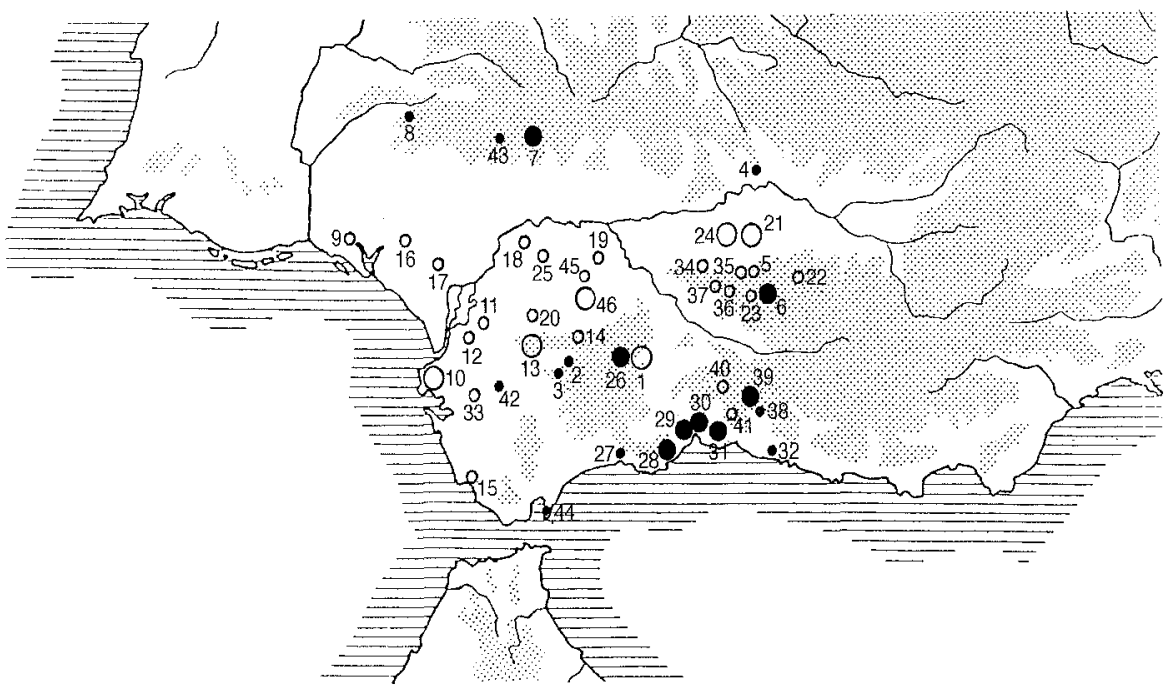

Fig. 6. Neolítico Final (Segunda mitad del IV milenio - Principios del II milenio) Hábitat: Cueva (•). Conjunto de cuevas (@). Superficie (O). Conjunto de superficie (O).

1. Cuevas de Ronda (Málaga). 2. Cueva de la Dehesilla (Algar, Cádiz). 3. Cueva del Parralejo (San José del Valle, Cádiz). 4. Cueva del Cañaveralejo (Adamuz, Córdoba). 5. Cueva de los Murciélagos (Zuheros, Córdoba). 6. Cuevas de Priego de Córdoba: Mármoles, Murcielaguina, Huerta de Anguita, Tocino, Inocentes, Cholones, Muerto. 7. Cuevas de Santiago (Cazalla de la Sierra, Sevilla). 8. Cueva de la Mora (Jabugo, Huelva). 9. Papauvas (Huelva). 10. Poblados del Puerto de Santa María y Rota (Cádiz): Las Viñas, Cantarranas, Base Naval. 11. El Cabezo (Lebrija, Sevilla). 12. Bustos (Trebujena, Cádiz). 13. Arcos de la Frontera (Cádiz): El Yugo, Los Bermejales. 14. Cabezo Hortales (Prado del Rey. Cádiz). 15. Barbate (Cádiz). 16. La Dehesa (Lucena del Puerto, Huelva). 17. El Judío (Almonte, Huelva). 18. Campo Real (Carmona, Sevilla). 19. San Pedro (Fuentes de Andalucía, Sevilla). 20. El Coronil (Sevilla). 21. Castro del Río (Córdoba). 22. La Mesa (Fuente Tójar, Córdoba). 23. El Esparragal (Priego de Córdoba). 24. Guadajoz Medio (Castro del Río, Córdoba). 25. Las Barrancas (Carmona, Sevilla). 26. Cuevas de Ronda (Málaga). 27. Cueva Pecho Redondo (Marbella, Málaga). 28. Cuevas de Benalmádena (Málaga). 29. Cuevas de Torremolinos (Málaga). 30. Cuevas de Málaga. 31. Cuevas de La Cala del Moral (Málaga). 32. Cueva de Nerja (Málaga). 33. El Cuartillo (Jerez de la Frontera Cádiz). 34. Fuente del Pez (Montilla, Córdoba). 35. Fuente del Carmen (Zuheros, Córdoba). 36. Fuente de las Palomas (Carcabuéy, Córdoba). 37. Llanos de Jarcas (Cabra, Córdoba). 38. Cueva de la Fájara (Canillas de Aceituno, Málaga). 39. Cueva del Espino (Alcaucín, Málaga). 40. Tajos de Gomer (Riogordo, Málaga). 41. Peña de Hierro (Cútar, Málaga). 42. Cueva de las Motillas (Jerez de la Frontera, Cádiz). 43. Los Covachos (Almadén de la Plata, Sevilla). 44. Cuevas de Gibraltar. 45. Los Álamos (Fuentes de Andalucía, Sevilla). 46. Marchena (Sevilla). 


\section{Cerámica}

En el neolítico final cambian las formas y se reduce drásticamente la decoración, con peculiaridades que anuncian el horizonte calcolítico. Persiste muy escasamente el tratamiento a la almagra, que por su deficiente calidad denominamos almagroide. Las toscas y simples decoraciones admiten series de estampillados circulares. Débilmente aparece la técnica pintada (Santiago Chica, Mármoles, Alcores). La escasa decoración se limita a series de groseros trazos incisos o impresos, siendo característicos los zig-zags paralelos verticales incisos en los hombros del vaso (Dehesilla).

Las formas tienden a abrirse con perfiles en $\mathrm{S}$, imponiéndose los bordes indicados, abruptos, que dan lugar a perfiles en $Z$, con carenas medias. Las asas se sustituyen por simples mamelones y lengüetas.

\section{Industria lítica}

La industria lítica tallada se empobrece, sobresaliendo las láminas de retoque continuo y persistiendo con debilidad el raspador nucleiforme, la laminita de borde abatido, las muescas, las fracturas retocadas, los denticulados y algunos geométricos trapezoidales (Santiago Chica) y triangulares (cuevas cordobesas). La anterior trayectoria de pulimentados continúa con hachas y azuelas, de la misma manera que los molinos y moletas, más abundantes.

\section{Industria ósea}

La industria del hueso sigue el proceso anterior con punzones de metápodos, de media caña, agujas, espátulas, cinceles y varillas planas y finas, haciendo su aparición los peines (Dehesilla).

\section{Adornos}

Los adornos personales disminuyen sus porcentajes, menos diversificados, persistiendo las cuentas de collar de piedra perforadas, las cuentas tubulares de hueso, incluso algunos brazaletes de mármol lisos arcaizantes (Mesa de Fuente Tójar, San José del Valle) (figura 7). 


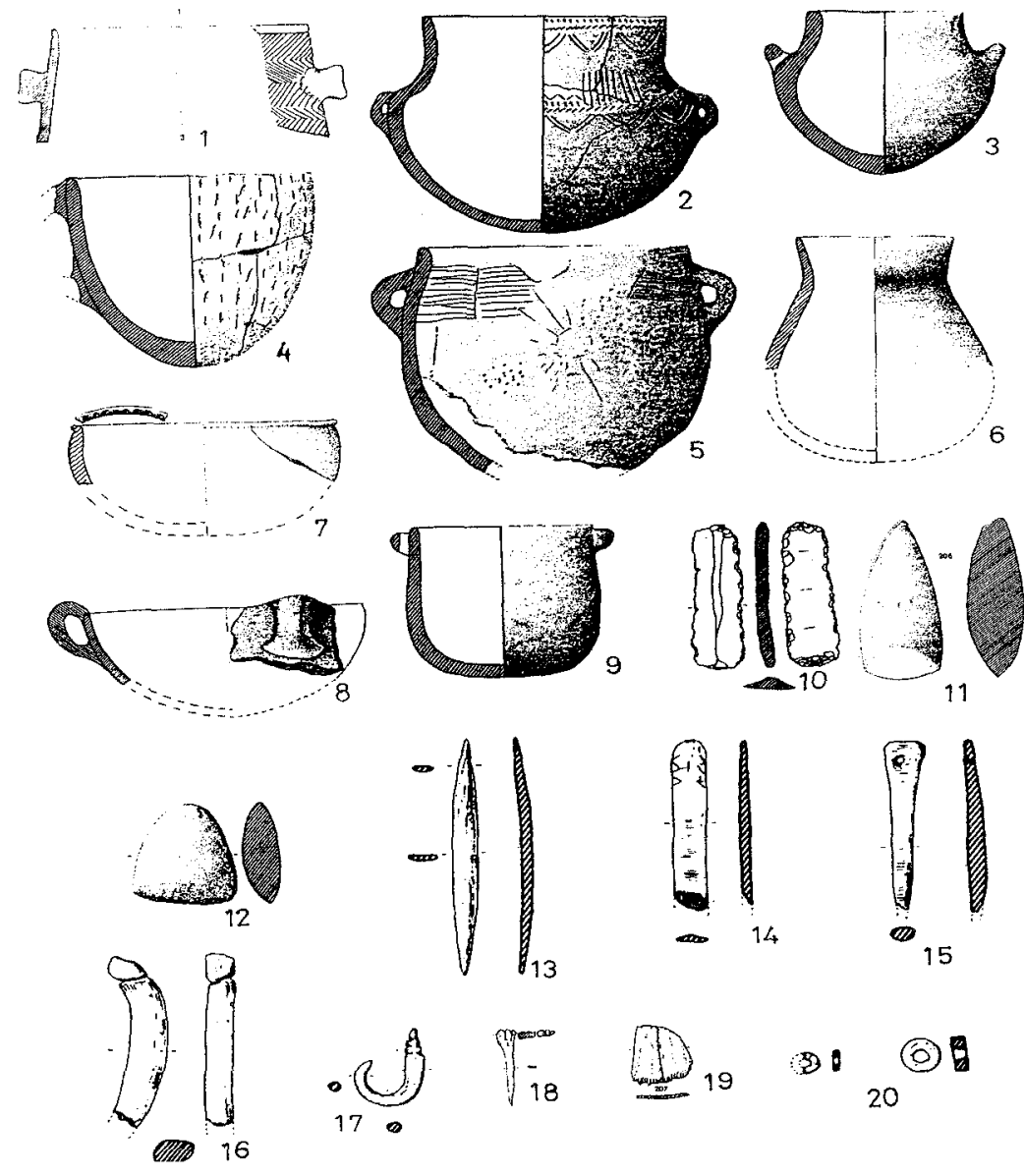

Fig. 7. Neolítico Final.

1. Vaso troncocónico con decoración de paralelas quebradas verticales incisas. 2. Vaso semiesférico con amplio gollete y decoración incisa. 3. Vaso ovoide con amplio gollete y asas-mamelón. 4. Vaso semiovoide con asa de cinta y decoración de trazos. 5. Vaso semiovoide con decoración incisa y puntillado de paralelas y esteliforme. 6 . Vaso de perfil en S. 7. Vaso semiesférico, borde indicado y dentado. 8. Vaso semiesférico con asa de cinta. 9. Vaso cilíndrico con asas mamelón. 10. Lámina de silex con retoque simple alterno. 11. Hacha de piedra pulimentada. 12. Azuela de piedra pulimentada. 13. Aguja de hueso biapuntada. 14. Varilla-espátula de hueso. 15. Aguja de hueso con ojo. 16. Colgante de spondylus. 17. Anzuelo de hueso. 18. Punzón sobre metapodio de ovicáprido. 19. Peine de hueso. 20. Cuentas discoidales de piedra.

Procedencia:

1 y 7: Cueva de la Dehesilla (Alga, Cádiz). 2, 3, 5, 9 y 17: Cueva de la Murcielaguina (Priego de Córdoba). 4: Cueva de los Inocentes (Priego de Córdoba). 6, 8, 11, 13, 18 y 19: Cueva Chica de Santiago (Cazalla de la Sierra, Sevilla). 10, 12-16, 20: Cueva de los Mármoles (Priego de Córdoba).

1 y 7 : según P. Acosta y M. Peciller. 6, 8, 11, 18 y 19: según P. Acosta. 2-5, 9, 10, 12-17, 20: según B. GaVILÁN. 


\section{Economía}

La agricultura cerealística se ha generalizado con el cultivo de trigo y cebada (Mármoles), penetrando en la costa malagueña (Nerja). El exponente de esta agricultura se confirma por la dispersión de los poblados de superficie por las campiñas, valles y zonas fértiles y, más concretamente, por los silos que llenan los yacimientos (Campo Real, Puebla del Río, Puerto de Santa María).

Según la fauna de Dehesilla y Parralejo, las especies domésticas predominan ya sobre la caza en una proporción decreciente del cerdo, ovicáprido, bóvido. En Santiago Chica se observa menor consumo de carne, prevaleciendo todavía la caza $(53 \%)$ sobre la fauna doméstica $(47 \%)$, con unos porcentajes de caballo $(47 \%)$, jabalí $(31 \%)$, ciervo $(14 \%)$, ovicápridos $(3 \%)$, corzo $(2,58 \%)$, liebre $(0,35 \%)$, conejo $(0,23 \%)$, galápago $(0,08 \%)$ y erizo $(0,03 \%)$. Debe destacarse la Marismilla, junto a la marisma del Guadalquivir, con función de producción y comercialización de la sal.

\section{Ritos funerarios}

Siguiendo el anterior hábito, se entierra en cuevas de habitación (Dehesilla), donde predominan los enterramientos infantiles. Se inicia la tendencia al enterramiento múltiple, según se desprende de los primeros megalitos que emergen, al parecer en el neolítico final, posiblemente de origen portugués alentejano, si nos atenemos a las fechas radiocarbónicas. Las primeras muestras megalíticas estarían representadas por algunos dólmenes complejos afines a las galerías cubiertas de Huelva (Pozuelo, Gabrieles). El conjunto de estructuras ya megalíticas, de tendencia circular, rectangular y en fosa, con enterramientos dobles o individuales de Alcalá del Valle (Cádiz), según sus ajuares con elementos neolíticos, son claro exponente de la temprana aparición del nuevo rito.

\section{Arte rupestre}

Prosigue dentro del estilo esquemático tanto en Sierra Morena como en las sierras del sur de Cádiz. Por los paralelos de cabras monteses incisas representadas en cerámicas del neolítico final de Nerja, cabe adscribir a este horizonte sus analogías rupestres. 


\section{Hábitat}

La utilización de la cueva como hábitat se restringe, sustituida por el poblado de superficie sobre paisajes más abiertos de la campiña y amplios valles. La proporción de hábitats de superficie duplica a los de cueva. El tamaño de los mismos es reducido, sin que alcance la hectárea, con fondos de cabaña circulares y zócalos de piedra o barro, con fosos, silos y trincheras de drenaje o basureros, tan característicos de la fase siguiente calcolítica.

\section{Yacimientos}

Prosigue la habitación en cueva en las sierras cordobesas de Cabra y Priego (Murciélagos, Mármoles, Murcielaguina, Tocino, Mina, Muerto), en las gaditanas (Dehesilla, Parralejo) y malagueñas (Serranía de Ronda) y especialmente en la costa malagueña (Botijos, Tesoro). Los yacimientos de superficie se multiplican en las zonas llanas de Sevilla (San Pedro, Las Barrancas, la Loma, Rancho de Pelotomar) y de Córdoba (Castro del Río, La Mesa, Morales, Esparragal), habitándose densamente el valle medio del Guadajoz (Molinillo Alto, San Joaquín, Viña Bonorato, Guta), el bajo Guadalquivir y las marismas (Marismilla, Carmona, Coronil, Puerto de Santa María, Rota) y el sur de Huelva (Judío, La Dehesa, Papauvas).

\section{Estadios}

Es difícil precisar las fases del neolítico final, pero a través de las estratigrafías podría adscribirse a una primera fase o fase $\mathrm{A}$ el nivel 5 del corte Dehesilla-81, el 4 de Parralejo B y el 8 de Santiago Chica-80, con una cronología entre el 3500 y 3000 a. C. A la fase B corresponderían en estos mismos yacimientos el nivel 4 de Dehesilla-81, el 3 de Parralejo B y el 7 de Santiago Chica-80, con una cronología presumible dentro de la primera mitad del III milenio a. C., con ligeras pervivencias según el conservadurismo de algunas zonas.

\section{Facies regionales}

Las facies del neolítico final siguen las pautas anteriores en las que se distinguen las sierras Subbéticas occidentales, la costa oriental de Cádiz 
y occidental de Málaga, la campiña sevillana, el bajo Guadalquivir, marismas sur de Huelva y la Sierra Morena, con ciertas modificaciones ante el protagonismo tomado por las tierras bajas y valles de ríos, donde la fertilidad será el gran aliciente demográfico y cultural con grandes núcleos de habitación.

\section{CALCOLÍTICO}

\section{Región considerada}

La uniformización cultural caracteriza el calcolítico, cuya eclosión demográfica se extiende por todas las comarcas de las provincias de Huelva, Sevilla, Córdoba, Cádiz y parte occidental de Málaga.

\section{Nombre de la cultura}

Según las etapas de la investigación, el calcolitico ha recibido diferentes nomenclaturas. Se han desechado los términos neoeneolítico por impreciso y genérico, y el de bronce I por erróneo, continuando los de edad del cobre y eneolítico, referentes aquí al calcolítico precampaniforme. Restringidamente también se usa el de cultura de los silos, igualmente aplicado al neolítico final, por esa característica de ciertos poblados de datación imprecisa. Incluso el generalizado término calcolítico no es totalmente real, ya que el cobre parece desconocerse en los inicios de esta cultura.

\section{Datación}

Disponemos para este horizonte de varias fechas radiocarbónicas. Los inicios del calcolítico en Santiago Chica se sitúan en el $3150 \pm 120$ a. C. y en la mina de cobre de Chinflón en el $2830 \pm 50$ y $2890 \pm 50$ a. C. La fase II de Papauvas, con platos carenados, ha sido fechada en $2890 \pm 120$ a. C. El poblado del Negrón ha dado las fechas de $2380 \pm 35$ y $2300 \pm 35$ a. C. De un momento más avanzado del III milenio tenemos el tholos de la Cabeza con fechas de $2100 \pm 105,1960 \pm 110$ y $1940 \pm$ 110 a. C. De todo este repertorio cronológico pueden deducirse dos fases, una inicial de la primera mitad del III milenio y otra avanzada de su segunda mitad. 


\section{CALCOLÍTICO}

\begin{tabular}{lccc}
\hline \multicolumn{1}{c}{ YACIMIENTOS } & LABORATORIOS & FECHAS B. P. CALIBRACIÓN B. C. \\
\hline Papauvas (Huelva) " & CSIC 85 & $4840 \pm 120$ & \\
Chinflón (Zalamea la Real, Huelva) & BM 1600 & $4840 \pm 50$ & \\
$"$ " & BM 1599 & $4780 \pm 50$ & \\
" & OX TL 200 e3 (II) & $4000 \pm 300$ & \\
El Negrón (Gilena, Sevilla) & & $4330 \pm 35$ & \\
$\quad$ " & & $4250 \pm 35$ & \\
Monturque (Córdoba) & Ugra 303 & $4120 \pm 160$ & $3095-2208$ \\
Papauvas (Huelva) IV & CSIC 654 & $4110 \pm 50$ & \\
\hline
\end{tabular}

\section{Extensión geográfica}

En el calcolítico, posiblemente por la eclosión y generalización de la agricultura cerealística, se asiste a un considerable aumento demográfico con la emergencia de grandes poblados que invaden los bordes del bajo Guadalquivir, la campiña sevillana, el sur de Cádiz, Huelva y especialmente Córdoba (figura 8).

\section{Cerámica}

La pauta, iniciada en el neolítico final, del predominio absoluto de cerámicas lisas se radicaliza en el calcolítico. Los vasos aumentan de tamaño con grandes recipientes para provisiones, siempre de pastas toscas. Se hacen comunes los grandes platos, al principio caranados, conviviendo inmediatamente con los de borde grueso o almendrado. Estos platos se extienden por Huelva, valle medio y bajo del Guadalquivir, Córdoba y costa malagueña, enrareciéndose conforme avanzan hacia Andalucía oriental. Otras formas son el cuenco semiesférico y abierto, el gran vaso de almacén de borde grueso entrante, el globular achatado y lenticular, el cilíndrico y troncocónico, apareciendo incluso vaso teriomorfo, representando aves o cuadrúpedos, de carácter funerario. Las cucharas del neolítico final continúan.

La cerámica decorada es rara, no obstante persiste la vieja tradición a la almagra, pero de inferior calidad, la pintada (Tarifa, Carmona, Valencina, Mesas de Asta, Pileta, sur de Córóoba) y las pastillas repujadas (Santiago Chica), surgiendo la técnica de la retícula bruñida (Valencina, Santiago Chica), característica de la posterior época tartesia. Otras técnicas decorativas son el puntillado, los trazos incisos, impresiones digitales y ungulares los bordes dentados y la peinada (figura 9). 


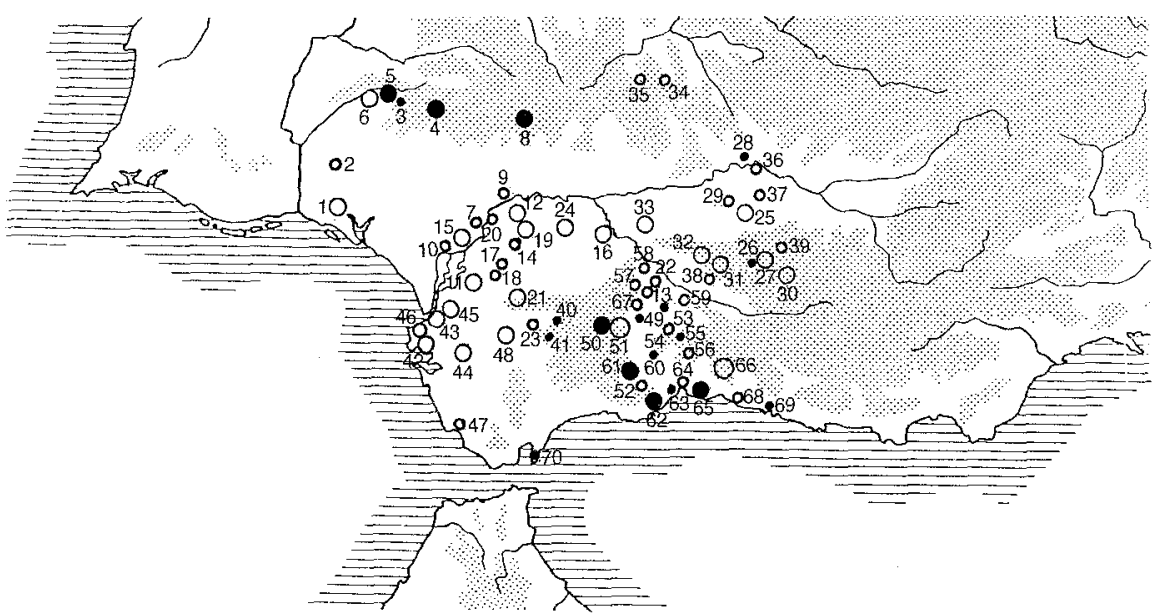

Fig. 8. Calcolítico (Principios del mil milenio - fines del II milenio)

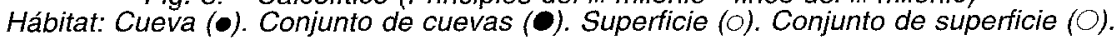

1. Huelva: Papauvas. El Rincón. 2. Cabezo de los Vientos (San Bartolomé de la Torre, Huelva), 3. Cueva de la Mora (Jabugo, Huelva). 4. Cuevas de Alájar (Huelva). 5. Cuevas de Aroche (Huelva): Agua (Fuentes del León), Cantera (Navahermosa), Mora (La Umbría), Covacho del Monje, Covacho Cerro del Castillo. 6. Poblados de Aroche (Huelva): Castillo de Maribarra. Los Ballesteros. Castillo de Mari-Lucas. Alto del Naranjo. Cerro Mariantes. San Sixto. Pico del Criado. Huerta del Picón. Sierra de la Víbora. Lomo Delgado. Pico del Castillo. Sierra Herrera. La Capota. La Garrapata. Solana del Torrejón. Cerro Borrero. Castillo de Torres. Cumbres de la Giralda. La Mazmorra II. 7. Valencina de la Concepción (Sevilla). 8. Cuevas de Santiago (Cazalla de la Sierra, Sevilla). 9. La Morita (Cantillana, Sevilla). 10. Chillar (Villamanrique de la Condesa, Sevilla). 11. Lebrija (Sevilla): San Benito. El Cabezo. Aceituno. Huerta de Abajo. Hoya de la Burra. Mesa del Castaño. Huerto. Quincena. Overo. Fuente de la Salud. Loma de Vegina. 12. Carmona (Sevilla): Campo Real. Alcaudete. Acebuchal. Santa Marina. Ranilla. Cortijo del Cerro. Haza de Haberes. Capilla. Barrancos. Chiste. Cuevalonga. Cortijo de San Juan. San Juan Alto. 13. El Negrón (Gilena, Sevilla). 14. Vereda de Alconchel (Mairena del Alcor, Sevilla). 15. Puebla del Rio (Sevilla): Silos. La Marismilla. 16. Ecija (Sevilla). 17. Utrera (Sevilla). 18. Mesa de Gandul (Alcalá de Guadaira, Sevilla). 19. El Viso del Alcor (Sevilla): La Alunada. Rancho del Zurdo. 20. Brenes (Sevilia). 21. El Coronil (Sevilla): El Algarve II, Morillas. La Frenadilla. Piedra Hincada. Aguaderilla II, Caserón I. Pescozal. Herrera. Amarguillo II, Los Morales. El Casar. El Jardel. Las Aguzaderas. Molino Pintado. Portichuelo. Coronil I, Tesorillo III. 22. Cueva del Puntal (Lora de Estepa, Sevilla). 23. La Fuensanta (Montellano, Sevilla). 24. Fuentes de Andalucia (Sevilla): San Pedro. Herradura I, Los Álamos I, Loma Lombriz. Verdejo Nuevo II, Los Cantones. Cerro Berrero 1. 25. Castro del Río (Córdoba): Los Morales. Los Almiares. Los Carambolos. Fuenteasneras. Guta. Tiñosa. Veleto. Viña Bonorato. 26. Cueva de la Detrita (Priego de Córdoba). 27. Priego de Córdoba: El Castillarejo. Torreón del Esparragal. 28. Cueva del Cañaveralejo (Adamuz, Córdoba). 29. Ategua (Santa Cruz, Córdoba). 30. Baena (Córdoba): Cerro Jesús. Torreparedones. 31. Montilla (Córdoba): Cerro Santa María. Cerro Triguillos. 32. La Rambla (Córdoba): La Minilla. Prádena. 33. Santaella (Córdoba): Olivar del Pósito. La Sendilla. 34. Sierra Palacios (Bélmez, Córdoba). 35. Los Delgados (Fuenteobejuna, Córdoba). 36. Llanete de los Moros (Montoro, Córdoba). 37. Cañete de las Torres (Córdoba). 38. Aguilar de la Frontera (Córdoba). 39. La Mesa (Fuente Tójar, Córdoba). 40. Cueva de la Dehesilla (Algar, Cádiz). 41. Cueva del Parralejo (San José del Valle, Cádiz). 42. Puerto de Santa María - Rota (Cádiz): Las Viñas. Cantarranas. La Dehesa. 43. Sanlúcar de Barrameda (Cádiz): El Hidalgo. Ebora. Cabeza Alcaide HI. Punta Espiritu Santo. Látigo de Monteagudo I, Haza del Moral. Norieta Grande. Cerro Palmar. Ventosilla I. La Alcántara. Al-Ventus. El Berral. Cerro Carnicería. Cerrotijo. Dehesa del Duque. La Estacaita. Las Grullas. La Maceta. Casita Palomares. El Redondón. La Rijerta Alta. 44. Jerez de la Frontera (Cádiz): Mesas de Asta. El Trobal. 45. Trebujena (Cádiz): Cerro de las Vacas. Cooperativa Nueva. Bustos. Las Monjas, 46. Chipiona (Cádiz): 19 poblados. 47. Zahora (Barbate, Cádiz). 48. Arcos de la Frontera (Cádiz): Aznar. Los Bermejales. Pantano de Bornos. Los Cabezuelos. Carretera Nueva. Carretera Aznar. Castillejos. Concejo. El Cuadrejón. Cuarto Adentro. Escuchagrano. Estación Jédula. Fuensanta. Jadramil. Cortijo de Jédula. Pantano. Plaza de Armas. Toril. Las Valderas. Sierra de Valleja. Vereda. Baja. 49. Cueva de las Palomas (Teba, Málaga). 50. Cuevas de Ronda (Málaga): Pileta, Gato. 51. Poblados de Ronda (Málaga): Acinipo. Montecorto. 52. Llano de la Virgen (Coin, Málaga). 53. Cueva de las Goteras (Mollina, Málaga). 54. Cerro Antequera (Antequera, Málaga). 55. Cueva del Toro (Antequera, Málaga). 56. Cerro García (Colmenar, Máaga). 57. Humilladero (Málaga). 58. Alameda (Málaga). 59. Cortijo de Alcaide (Villanueva de Algaida, Málaga) 60. Cueva de los Murciélagos (Ardales, Málaga). 61. Alozaina (Málaga): Cueva del Jorox. Cueva del Algarrobo. 62. Benaimádena (Málaga): Cueva del Sáhara. Cueva de los Botijos. 63. Cueva del Tesoro (Torremolinos, Málaga). 64. San Telmo (Málaga). 65. Cala del Moral (Málaga): Cueva de la Pulsera. Cueva del Higueron. 66. Velez Málaga: Peña de Hierro. Capellanía. Cerca Niebla. Cerro de la Negreta. 67. Los Castillones (zona de Campillos, Málaga). 68. Morro de Mezquitilla (Algarrobo, Málaga). 69. Cueva de Neria (Málaga). 70. Cuevas de Gibraltar. 

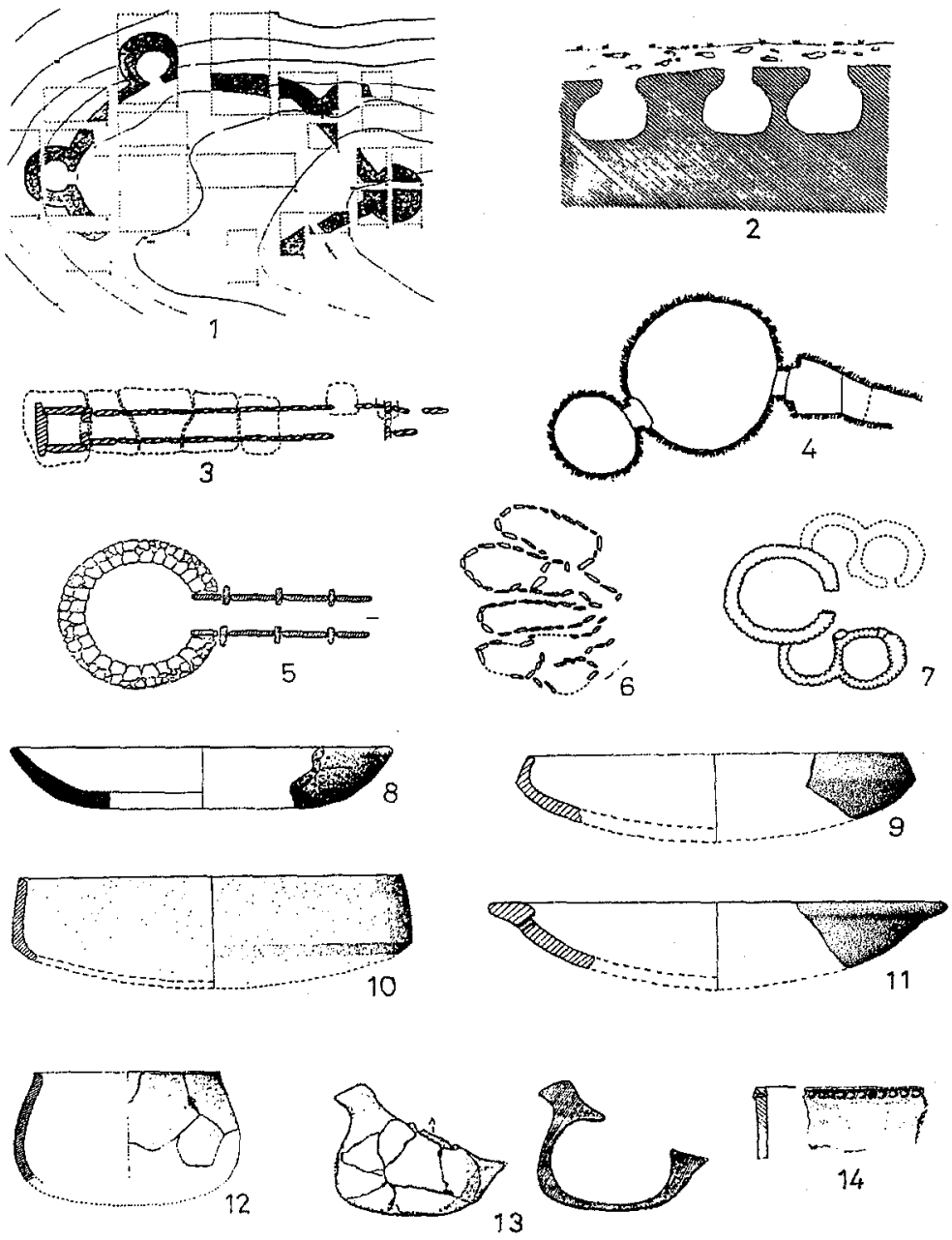

Fig. 9. Calcolitico.

1. Planta del poblado del Cabezo de los Vientos. 2. Perfiles de silos. 3. Dolmen de corredor. 4. Sepulcro en cueva artificial. 5. Tholos. 6. Doimén múltiple. 7. Conjunto funerario. 8. Plato de tendencia troncocónica. 9. Plato carenado. 10. Id. 11. Plato de borde grueso o almendrado. 12. Cuenco cerrado. 13. Vaso ornitomorfo. 14. Vaso decorado con pastillas repujadas.

Procedencia:

1: San Bartolomé de la Torre (Huelva), 2: Cerro de San Benito (Lebrija, Sevilla). 3. Cueva de Viera (Antequera, Málaga). 4: Alcaide (Villanueva de Algaida, Málaga). 5, 7, 13: tholoi de La Zarcita (Santa Bárbara, Huelva). 6: El Pozuelo (Zalamea la Real, Huelva). 8: Cueva de las Palomas (Teba, Málaga). 9-11, 14: Cueva Chica de Santiago (Cazalla de la Sierra, Sevilla). 12: El Papauvas (Huelva).

1: según F. Piñón. 2: según A. CARo. 3: según M. Gómez-Moreno. 4: según S. Giménez. 5, 6 y 13: según C. CERDÁN. 7: según M. ${ }^{a}$ BELÉN. 8: según J. FERRER. 9-11, 14: según $P$. ACOSTA. 12: segun J. C. MARTIN. 
Industria lítica

La industria lítica tallada aumenta de volumen con grandes lascas y láminas retocadas (Montecorto) y con talla envolvente con función de puñales y alabardas (Huelva). Aparecen los foliáceos con abundantes puntas de flecha de base cóncava, recta y romboidales. En la Dehesilla el utillaje lítico tiene tipologías de láminas de retoque continuo (38\%), raspadores $(25 \%)$, dientes de hoz (13\%), muescas $(12 \%)$ y denticulados $(12 \%)$. En el sur de Córdoba predominan los foliáceos, truncaduras, muescas y perforadores. Los geométricos alcanzan su apogeo en los dólmenes de Huelva y fase II de Papaúvas. En el calcolítico de Santiago Chica hay ejemplos de buril simple, fractura retocada, lámina de retoque continuo, de retoque abrupto, perforador simple, muescas, crestas y puntas de flecha de base cóncava. Los pulimentados, muy generalizados, son abundantes en Dehesilla y Santiago Chica con ejemplos de hachas, azuelas, alisadores y cinceles. Los molinos y moletas son normales.

\section{Industria ósea}

Aumenta más en cantidad que en variedad. En Dehesilla predominan los punzones de media caña, los dientes preparados y las espátulas y en Santiago Chica los punzones finos y espátulas. Perduran los peines y se utiliza el marfil como materia prima exótica, destacándose el colmillo de elefante del dolmen de Matarrubilla.

\section{Metalurgia}

La metalurgia del cobre, doméstica, se inicia en un momento avanzado del calcolítico. La ausencia de metalurgia en sus inicios no es obstáculo para hablar de un calcolítico en el sentido cultural y socio-económico, sin que su aparición provoque cambios importantes y sin que afecte a la economía. Los primeros instrumentos de cobre se reducen a pequeños punzones, siguiendo las hachas trapezoidales planas fabricadas in situ (Los Morales, Puebla del Río), según los moldes hallados. Pronto son comunes los puñales de lengüeta y cinceles (Viña Bonorato). El uso del oro parece de un momento avanzado (Montilla, sepulcro de la Pastora, Algarbes).

\section{Adornos}

Proliferan los adornos de tipo colgante y las cuentas de collar de piedra, hueso, marfil y cerámica, con formas discoidales, ovales, bicónicas, cilíndri- 
cas y las placas perforadas. Se introducen como materias extrañas el marfil y tipos de piedras verdosas, halladas en los ajuares dolménicos (figura 10).

\section{Economia}

Se coloniza definitivamente todo el fértil valle del Guadalquivir y afluentes, explotándose sistemáticamente el territorio a base de una agricultura rotatoria y de policultivo cerealísta. La floreciente agricultura fue causa/efecto del considerable aumento demográfico con nuevos y más amplios establecimientos. La dieta vegetal depredatoria se trueca por la de producción cerealística con la modalidad de polentas, según la abundancia de silos y de platos de mesa. Entre los análisis de fauna destacan los de Dehesilla, Santiago Chica y Papaúvas. En Dehesilla predomina la doméstica $(75 \%)$ sobre la salvaje (25\%), siendo por orden decreciente el ovicáprido $(44 \%)$, bovido $(18 \%)$, cerdo $(13 \%)$, ciervo $(17 \%)$, jabalí $(2 \%)$, conejo $(0,73 \%)$, y estando presente el perro, lince, tejón y los caracoles. En Santiago Chica prosigue la caza con predominio, como en anteriores fases, con un $97,51 \%$ destacándose el alto porcentaje de ciervo $(31,72 \%)$ y jabalí $(31,50 \%)$.

El tejido se desarrolla en el calcolítico, confirmado por las frecuentes pesas de telar en forma de placas cerámicas y de crecientes con los extremos perforados.

\section{Ritos funerarios}

Con el calcolítico se asiste al cambio de rito funerario, de individual a colectivo, fenómeno que se observa en las cuevas naturales y en la implantación de los grandes sepulcros megalíticos e hipogeos. Su tipología adquiere una variedad inusitada en función de las influencias recibidas occidentales y de la específica geología de las zonas. En el tránsito al calcolítico todavía persiste en enterramiento individual en fosa (Papaúvas I) o en pequeñas estructuras de ortostatos (San José del Valle).

El tipo más común es el llamado sepulcro de corredor con cámara poligonal, de amplia cronología y pervivencias. La Galería cubierta, iniciada en la fase I se extiende desde el Guadiana por Sierra Morena, con plantas en $V$, irregulares, con cámaras múltiples, cubiertas por túmulo, penetrando en la Subbética gaditana y malagueña. El dolmen simple o cista megalítica, excepcional en Sierra Morena, se presenta en Huelva y Sierra de Cádiz. El tholos o cámara circular de falsa cúpula y corredor predomina en 


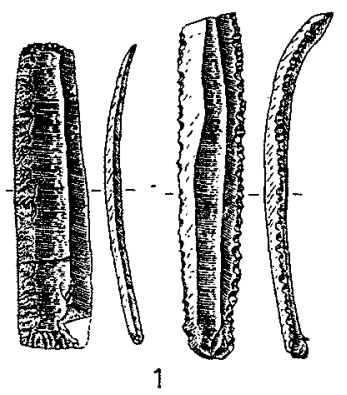

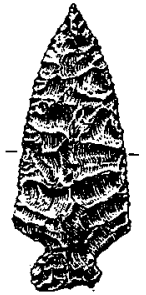

2
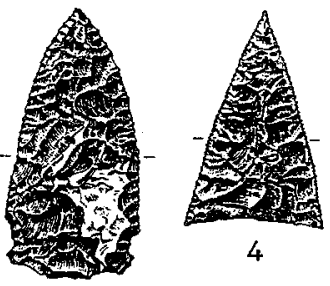

4
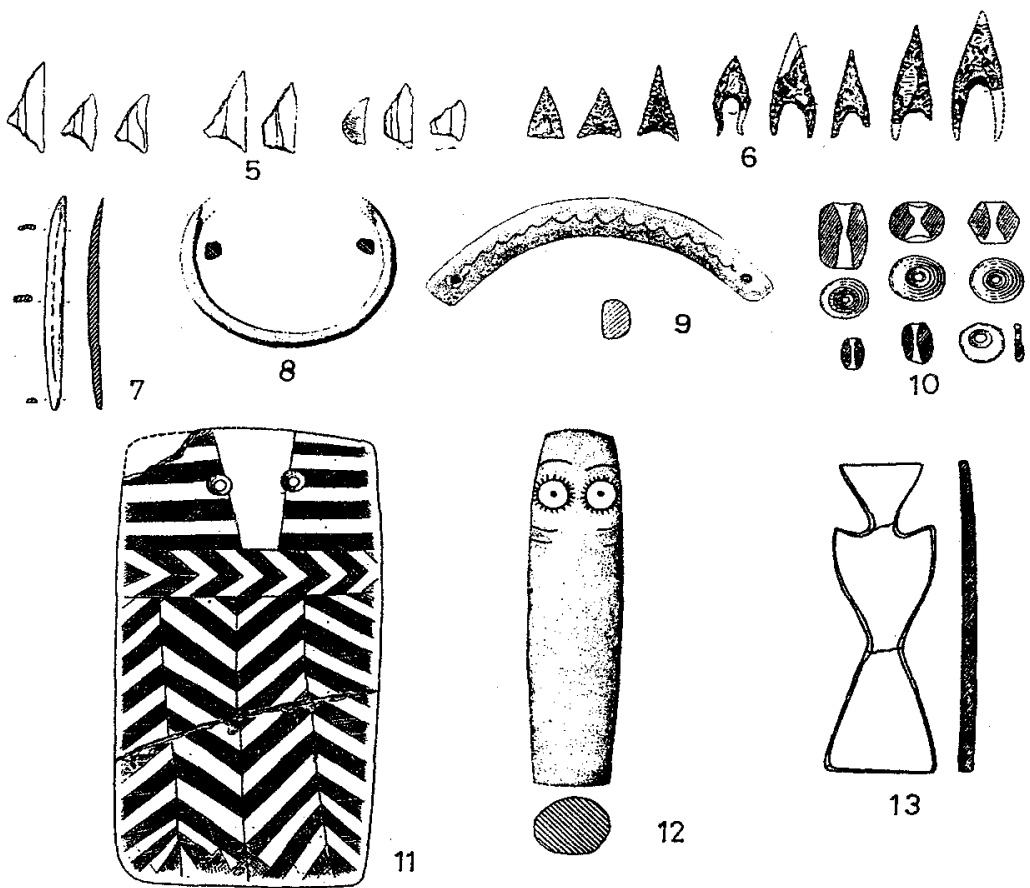

13

12

Fig. 10. Calcolítico.

1. Láminas de silex retocadas. 2. y 3. Alabardas de silex. 4. Puñal de silex. 5. Microlíticos geométricos de silex. 6 . Puntas de flecha de silex, de base recta, cóncava y aletas. 7 . Aguja de hueso. 8. Brazalete de pectúnculo. 9. Pesa de telar en creciente de cerámica. 10. Cuentas de collar de piedra. 11. Idolo-placa de esquisto. 12. Idolo-cilindro de mármol. 13. Idolo triangular de hueso.

Procedencia:

1-4, 6: La Zarcita. 5, 10 y 13: El Pozuelo (Zalamea la Real, Huelva). 7: Cueva de los Mármoles (Priego de Córdoba). 8: Cueva de la Murcielaguina (Priego de Córdoba). 9: Cueva Chica de Santiago (Cazalla de la Sierra, Sevilla). 11: Aljaraque (Huelva). 12: Cerro de las Vacas (Trebujena, Cádiz).

1-6, 10, 11 y 13: según C. Cerdán y G y V. Leisner. 7 y 8: según B. Gavilán. 9: según P. Acosta. 12: según A. Caro. 
el bajo valle del Guadalquivir. La cueva artificial, versión hipogea del tholos, se extiende por zonas bajas sedimentarias, enrareciéndose progresivamente hacia el este. Frecuentemente ha sido confundida con los silos de los poblados, reutilizados ocasionalmente como enterramientos y osarios (Las Viñas).

Los megalitos coinciden en elementos comunes como puertas, cámaras secundarias, pavimentos de losas, túmulos, ortostatos, mampuestos y técnicas mixtas. Ocasionalmente disponen de compartimentos y pilas cultuales. Entre los ajuares, aparte de los de carácter doméstico, como cerámicas y utillaje oseo y lítico, destacan los bienes de prestigio de cobre, oro y marfil, los elementos cultuales como los ídolos en sus variedades cilindro, cruciforme, placa grabada, antropomorfo y báculo.

\section{Arte rupestre}

Representa el apogeo del arte rupestre esquemático en abrigos rocosos y raramente en el interior de las cuevas (Pileta, Nerja). La temática prefiere los geometrismos simbólicos, pectiniformes, zigzags, esteliformes, trazos inconemos, de difícil significado. Su cronología se deduce de las cerámicas llamadas simbólicas y de algunas representaciones grabadas en dólmenes (Cabrieles, Soto). Sus núcleos principales son la Sierra Morena y sur de Cádiz.

\section{Habitat}

Expandido por todo el territorio, el habitat calcolítico tiene su máxima expresión en el bajo Guadalquivir con emplazamientos en espacios abiertos, fértiles y en puntos estratégicos defendibles de pasos naturales, formando extensos poblados repletos de silos, trincheras y fondos de cabaña. Se destacan los poblados de las comarcas de Castro del Río, Lebrija, Carmona, Valencina de la Concepción, Sanlúcar, Gilena, Gines, Ecija, El Coronil, Puerto de Santa María, Rota y, especialmente Papaúvas (Huelva). Algunos poblados alcanzan las 10 hectáreas como Valencina o Las ViñasCantarranas (Puerto de Santa Maria). Las viviendas son cabañas de planta circular u oval con diámetros que llegan a $4,50 \mathrm{~ms}$. (Papaúvas) y sus superestructuras, de piedra, barro, adobes, postes y ramaje. Las trincheras, interpuestas entre las cabañas, parecen tener función de basureros o elementos de drenaje de los silos. Aparte de los poblados en llanura sin defensas artificiales aparentes, existen los fortificados como el Cabezo de 
los Vientos, especie de fortin de 39 por $17 \mathrm{~ms}$. con seis torres circulares, hogares exteriores a las cabañas y sin restos de metalurgia.

\section{Yacimientos}

Los principales yacimientos se concentran a orillas del Guadalquivir medio y bajo, pero en general se extienden por todo el territorio de Huelva (Papaúvas, Rincón, Cabezo de los Vientos, Chapas), Sevilla (Valencina, La Morita, Chillar, Lebrija, Marismilla, Carmona, Mairena del Alcor, Gilena, Ecija, Utrera, El Coronil, Fuentes de Andalucía, Montellano), Córdoba (Castro del Río, Priego, Cabra, Ademuz, Ategua, Baena, Montilla, La Rambla, Santaella, Bélmez, Fuenteobejuna), Cádiz (Sanlúcar de Barrameda, Ebora, Cerro de las Vacas, Puerto de Santa María, Rota, El Gastor, Mesas de Asta, Arcos de la Frontera, Barbate, Tarifa) y parte oeste de Málaga.

\section{Estadios}

A través de las escasas estratigrafías verticales (Dehesilla, Santiago Chica) y horizontales (Papáuvas, Cabezo de los Vientos) y por el registro arqueológico, podrían admitirse dos fases, la inicial en la primera mitad del III milenio y la avanzada en la segunda mitad. En la Dehesilla corresponden al calcolítico los niveles 3 - 1 y en Santiago Chica el nivel 6 pertenecería a la fase antigua y el 5 a la avanzada. En Papaúvas se han distinguido cuatro fases $I^{\underline{a}}$ ) de fines del IV a principios del III milenio, IIa $) 2900$ - $2700.1 I^{\mathrm{a}}$ ) $2700-2600$ y IV르) $2600-2300$ a.C.

\section{Facies regionales}

Las facies regionales se acomodan a lo expuesto en el apartado de «Extesión geográfica» en función de las comarcas naturales.

\section{CAMPANIFORME}

\section{Región considerada}

El calcolítico campaniforme ocupa toda la región considerada, relativa a las provincias de Huelva, Sevilla, Córdoba, Cádiz y parte occidental de Málaga. 
Nombre de la cultura

La cultura, de transición al bronce, ha sido denominada Millares - Vilanova de San Pedro II, eneolítico y calcolítico final e, incluso, cultura de los Alcores por la frecuencia del vaso campaniforme tipo CarmonaAcebuchal, muy tardío.

\section{Datación}

Varias son las fechas radiocarbónicas obtenidas. El campaniforme de Monturque (Córdoba) dio la fecha de $2170 \pm 160$, que calibrada, equivale a 3095-2208 a.C., presumiblemente alta. El horizonte IV de Papaúvas, sin vaso campaniforme, se fechó en $2160 \pm 50$ a.C. La fecha de $3380 \pm 150$ B.P. de Valencina de la Concepción, calibrada, equivale a 1900 - 1550 a.C., disponiendo en el contiguo tholos de la Cabeza de las fechas sin calibrar de $2100 \pm 105$ y $1960 \pm 110$ a.C. La mina de cobre de Chinflón se fechó por termoluminiscencia en el $2050 \pm 300$ a.C. El horizonte con vaso campaniforme del Cerro del Berrueco (Medinasidonia) dio una fecha de $1680 \pm 80$ a.C. y la cueva de las Palomas de Teba (Málaga) entregó dos fechas sin calibrar, $1600 \pm 130$ y $1470 \pm 100$ a.C. Por estos datos sería posible atribuir al campaniforme un lapso de tiempo entre el $2200 / 2100$ y el 1500 a.C.

\section{CAMPANIFORME}

\begin{tabular}{|c|c|c|c|}
\hline YACIMIENTOS & LABORATORIOS & FECHAS B. P. & CALIBRACIÓN B. C. \\
\hline \multicolumn{4}{|l|}{ Cerro de la Cabeza (Valencina de } \\
\hline la Concepción, Sevilla). Tholos & I- 10.187 & $4050 \pm 105$ & \\
\hline " $\quad$ " & GIF 4028 & $3910 \pm 110$ & \\
\hline Valencina de la Concepción (Sevilla) & Ugra 72 & $3380 \pm 150$ & $1900-1550$ \\
\hline \multicolumn{4}{|l|}{ Cerro de la Cabeza (Valencina de } \\
\hline la Concepción, Sevilla). Tholos & & $3890 \pm 110$ & \\
\hline Monte Barrueco (Medinasidonia, Cádiz) & & $3620 \pm 80$ & \\
\hline C. de las Palomas (Teba, Málaga) & Ugra 198 & $3550 \pm 130$ & \\
\hline " " " & Ugra 177 & $3520 \pm 130$ & \\
\hline$"$ & Ugra 161 & $3420 \pm 100$ & \\
\hline
\end{tabular}

\section{Extensión geográfica}

Los yacimientos del horizonte campaniforme se extienden por las cuatro provincias citadas de Huelva, Sevilla, Córdoba, Cádiz y el oeste de Málaga (figura 11). 


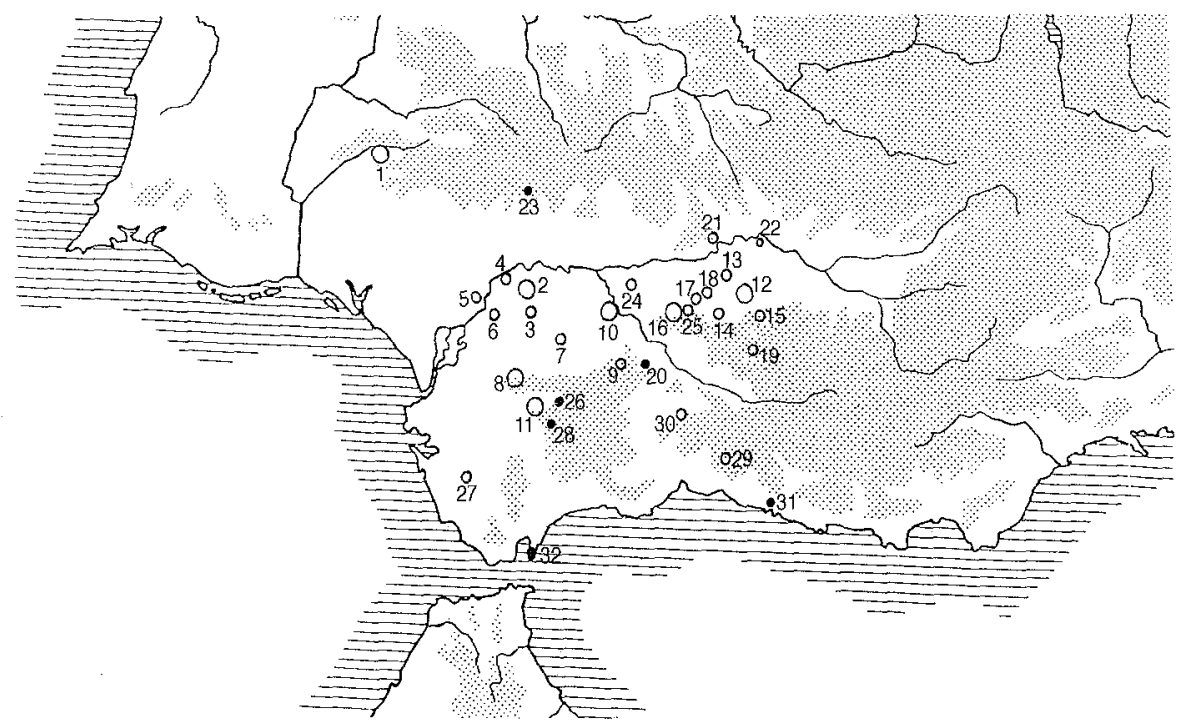

Fig. 11. Campaniforme (finales del II milenio-mediados del I milenio)

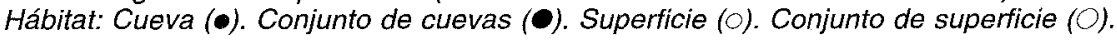

1. Aroche (Huelva): Castillo de Mari-Lucas. Solana de la Cabeza. San Sixto. Pico del Criado. Covacho del Monje. 2. Carmona (Sevilla): Acebuchal. Alcaudete. Santa Marina. La Batida. Entremalo. Los Alamos. Las Cumbres. 3. Rancho del Zurdo (Viso del Alcor, Sevilla). 4. Brenes (Sevilla). 5. La Algaba (Sevilla). 6. Universidad Laboral (Sevilla). 7. Marchena (Sevilla). 8. El Coronil (Sevilla). 9.Osuna (Sevilla). 10 Ecija (Sevilla). 11. Montellano (Sevilla): Pancorvo. Las Peñuelas. 12. Castro del Río (Córdoba): Guta. Los Carambolos. Tiñosa. Veleto. Los Almiares. 13. Ategua (Santa Cruz, Córdoba). 14. Cerro Triguillos (Montilla, Córdoba). 15. Cerro Jesús (Baena, Córdoba). 16. Santaella (Córdoba): La Sendilla. Olivar del Pósito. 17. La Minilla (La Rambla, Córdoba). 18. Montemayor (Córdoba). 19. Torreón del Esparragal (Priego de Córdoba). 20. Cueva del Puntal (Lora de Estepa, Sevilla). 21. Córdoba. 22. Llanete de los Moros (Montoro, Córdoba). 23. Cuevas de Santiago (Cazalla de la Sierra, Sevilla). 24. Fuente Paimera (Córdoba). 25. Montalbán (Córdoba). 26. Cueva de la Dehesilla (Algar, Cádiz). 27. Monte Berrueco (Medinasidonia, Cádiz). 28. Cueva del Parralejo (San José del Valle, Cádiz). 29. Cerro Capellanía (Vélez Málaga). 30. Arastipi (Antequera, Málaga). 31. Cueva de Nerja (Málaga). 32. Cuevas de Gibraitar.

\section{Cerámica}

Las formas cerámicas son una evolución del calcolítico, con persistencia de los platos de borde grueso. La decoración interna de algunos platos, con la técnica de la retícula bruñida, tiene ejemplos en el tholos de la Cabeza, en el Acebuchal, Santiago Chica y los Morales (Castro del Río). Esporádicamente en algunas cerámicas persiste la decoración pintada, puntillada, grabada e incisa junto con el viejo tratamiento a la almagra. Según los hallazgos, naturalmente en función de la intensidad de las 
prospecciónes, existen dos núcleos de vaso campaniforme, el sur de Córdoba (Castro del Río, Hornachuelos, Baena, Córdoba, La Rambla, Ategua, Montilla, Santaella) y los Alcores sevillanos (Carmona-Alcalá de Guadaira).

El campaniforme de tipo marítimo aparece en Huelva (Trigueros, Zarcita), Sevilla (Carmona, Acebuchal, Gandul, Ecija, Aznalcázar), Córdoba (Castro del Río); el tipo Cienpozuelos, en Córdoba (Hornachuelos) y Sevilla (Marchena), el tipo Palmela en Sevilla (dolmen del Vaquero) y Málaga (Montecorto) y el tipo Carmona y Acebuchal, en los Alcores sevillanos.

\section{Industria lítica}

Prosigue una macroindustria, bien representada en talleres como Montecorto (Ronda), donde abundan las grandes lascas y láminas retocadas. Las puntas de flecha, con predominio de las de base cóncava, conviven con las grandes piezas foliáceas con tipologías de puñales y alabardas, imitaciones líticas de prototipos de cobre. El calcolítico final de la cueva Chica de Santiago, del horizonte campaniforme, presenta un repertorio de industria lítica tallada compuesto de láminas de retoque directo, muescas, raspadores dobles y puntas de flecha de base recta y cóncava. Los pulimentados prosiguen como anteriormente.

Industria ósea

La industria ósea dispone de un repertorio virtualmente análogo al de la fase anterior, pero con predominio de punzones, algunos con mango cilíndrico (dolmen de Soto), y espátulas.

\section{Metalurgia}

Se generaliza la metalurgia del cobre, siempre en pequeña escala, diversificándose los artefactos como puntas de flecha tipo Palmela (Fuente Tójar), cinceles, punzones (Trigueros), hachas (Santiago Chica), sierras, puñales de lengüeta (Cañada del Carrascal) y con escotaduras laterales. Se trata de una industria doméstica, según la presencia esporádica de crisoles (Acebuchal H), escorias (Acebuchal H, Guta) y martillos de minero (Riotinto). 

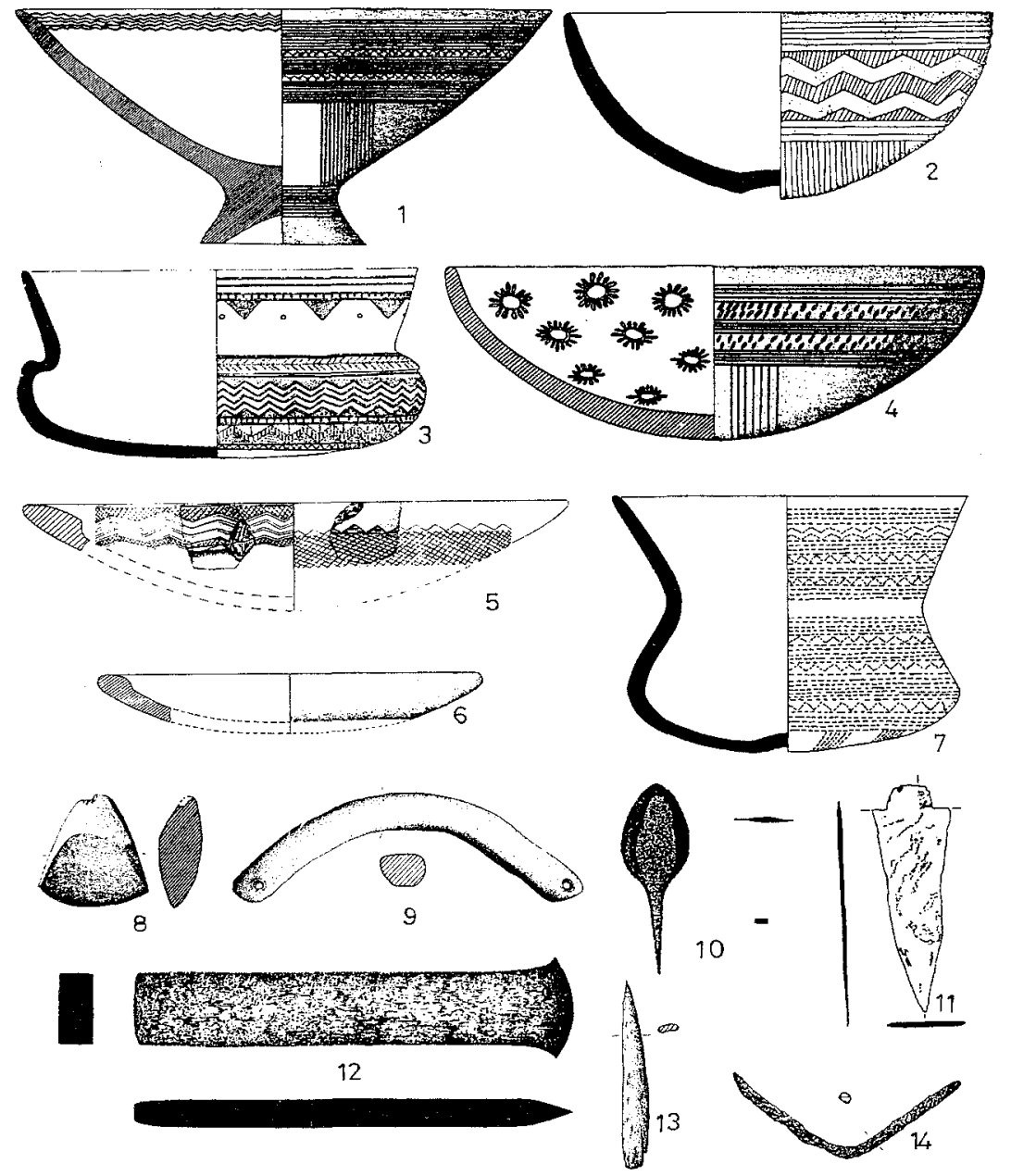

Fig. 12. Campaniforme.

1. Copa campaniforme incisa. 2. Cuenco campaniforme inciso. 3. Cazuela campaniforme incisa. 4. Cuenco campaniforme inciso. 5. Plato campaniforme inciso-boquique-exciso. 6. Plato de borde almendrado. 7. Vaso campaniforme tipo almeriense. 8. Azuela de piedra pulimentada. 9. Pesa de telar en creciente de cerámica. 10. Punta de flecha de cobre tipo Palmela. 11. Puñal de cobre de lengüeta. 12. Hacha rectangular de cobre. 13. Aguja plana de hueso. 14. Punzón de cobre.

Procedencia:

1 y 4: Olivar del Pósito (Santaella, Córdoba). 2, 5 y 10: Lebrija (Sevilla). 6, 9, 13 y 14: Cueva Chica de Santiago (Cazalla de la Sierra, Sevilla). 3: El Acebuchal (Carmona, Sevilla). 7: Ecija (Sevilla). 8: Cueva de los Mármoles (Priego de Córdoba). 11: Fuente Palmera (Córdoba). 12: Cerro de las Vacas (Trebujena, Cádiz).

1 y 4: según L. A. LOPEZ. 2, 10 y 12: según A. CARO. 3, 7 y 11: según J.R. HARRISON. 5: según M. Pellicer y P. Acosta. 6, 9, 13 y 14: según P. Acosta. 8: según B. Gavilán. 
Adornos

Sobresalen las cuentas de collar discoidales, cilíndricas, toneliformes, fabricadas en piedra, concha, hueso y marfil. Los botones de hueso o marfil con perforación en $V$ son raros, a diferencia de Andalucía oriental. Se pone de moda el llamado brazalete de arquero y los vasos de piedra con decoraciones grabadas (Gandul) de influencia almeriense o portuguesa (figura 12).

\section{Economía}

Prosigue la agricultura cerealística, según manifiestan los abundantes dientes de hoz de silex y los silos de los poblados. Respecto a la fauna se dispone de la estadística de Santiago Chica, establecimiento temporal de caza, donde la fauna salvaje sigue predominando $(86 \%)$ sobre la doméstica $(13 \%)$, con porcentajes decrecientes de ciervo $(39,42 \%)$, jabali $(25 \%)$, ovicáprido $(18 \%)$, bóvido $(13 \%)$, lobo $(2,21 \%)$, corzo $(1,62 \%)$, conejo $(0,6 \%)$, galápago $(0,04 \%)$ y con simple presencia de perdiz y perro. La industria textil sigue vigente, según los frecuentes hallazgos de cilindros curvos cerámicos con extremos perforados, usados como pesas de telar y fusayolas.

\section{Ritos funerarios}

Parece que la sociedad entra en crisis por la constante reutilización de anteriores sepulcros megalíticos, tholoi y cuevas artificiales, indicativas de un horizonte de transición hacia el enterramiento doble o individual en grandes cistas (Montilla) y fosas con nicho (Las Canteras de Gandul), prosiguiendo, como elementos cultuales, los ídolos antropomorfos de piedra, hueso o marfil (Santiago Chica, tholos del Cerro de la Cabeza) y otros tipos anteriores con predominio de los ídolos cilíndricos de mármol.

\section{Arte rupestre}

La crisis del campaniforme debió repercutir en el arte rupestre, en el que continúa el esquematismo simbólico con variados geometrismos tanto en Sierra Morena como en Cádiz. 
Habitat

Desaparecen ciertos poblados de superficie, prosiguiendo otros (Acebuchal, Gandul, Monturque, XI-IX, Carmona, Cabezo de Lebrija) e iniciándoșe otros (Caramilo, La Algaba, Cerro del Berrueco), con cabañas de planta circular, más toscas que en el horizonte anterior, rodeadas de silos.

\section{Yacimientos}

A pesar de la crisis demográfica, acentuada en el bronce, persiste el habitat en yacimientos anteriormente iniciados en el sur de Córdoba (Guta, Los Carambolos, Tiñosa, Veleta, Almiares, Ategua, Triguillos, Prádena, Jesús, Sendilla, Minilla, Calva, Cabezuelas, Torreón del Esparragal) y en Sevilla (Carmona, Los Alcores) y emergiendo otros nuevos como El Carambolo, Acebuchal, Monte Berrueco, el Estanquillo.

\section{Estadios}

Solamente se han precisado posibiles fases en Santiago Chica, donde el nivel 4 correspondería a una primera fase, fechada a finales del III milenio, y los niveles $3-1$, revueltos, a principios del II milenio. No obstante, la fase avanzada, según la cronología atribuída al campaniforme tardío tipo Carmona y Acebuchal, pudo haber perdurado hasta mediados del II milenio, momento sincrónico a un bronce impreciso deficientemente conocido y coetáneo al Argar A de Andalucía oriental.

\section{Facies regionales}

Con una acentuada pobreza cultural y con grandes lagunas de conocimiento, las facies regionales del campaniforme seguirían la misma pauta que la fase anterior calcolítica.

\section{EL NEOLITICO Y CALCOLÍTICO DE ANDALUCIA OCCIDENTAL: SÍNTESIS}

Dada la extensión geográfica y la diversidad de facies culturales con características específicas dentro del neolítico y calcolítico andaluz, resulta congruente dividir Andalucía en dos grandes zonas, la occidental, que 
incluiría las provincias de Huelva, Sevilla, Córdoba, Cádiz y la parte occidental de Málaga, y la oriental, que abarcaría las provincias de Almería, Jaén, Granada y la parte oriental de Málaga. En esta división el problema radica en el sur de la provincia de Málaga, políticamente adscrita en Andalucia oriental y culturalmente a la zona occidental.

Geográficamente, atendiendo a los accidentes geológicos, orográficos e hidrográficos, Andalucía occidental podría subdividirse de norte a sur en seis comarcas, que serian, la Sierra Morena, al norte y noroeste del Guadalquivir, relacionada en el neolítico con el suroeste de la Cordiliera Subbética y en el calcolítico con el Alentejo portugués; el Valle Medio y Bajo del Guadalquivir, con entidad propia, se relaciona en el neolítico antiguo y medio con el foco nuclear de las Sierras Subbéticas occidentales, manifestando en el calcolítico avanzado ciertas relaciones, posiblemente marítimas, con los ricos núcleos de las bocas del Tajo y Almería, horizontes de Vilanova y Millares; las campiñas sevillana y cordobesa, al sureste y sur respectivamente del Guadalquivir, con un neolítico antiguo y medio con raíces en la zona nuclear Subbética y con un calcolítico participante de la cultura del valle del Guadalquivir; el sur de Huelva, con un neolítico medio-final y un calcolítico ligado con la costa meridional portuguesa, el foco nuclear de las sierras Subbéticas occidentales y, finalmente, la costa occidental malagueña, con un neolítico antiguo y medio dependiente igualmente del foco nuclear Subbético y con un calcolítico relacionado con todo el suroeste.

Según el estado actual de las investigaciones, pese a las lagunas existentes, el neolítico de Andalucía occidental es, junto con el de Levante y Cataluña, el mejor conocido de la Península, aunque con un número limitado de yacimientos estudiados, como las cuevas de la Dehesilla, Santiago Chica de Cazalla, Murciélagos de Zuheros, Mármoles, Hoyo de la Mina, Cabezo de Lebrija. Son insuficientes las prospecciones realizadas por Huelva, Sierra Morena, Sierra de Cádiz y campiñas sevillana y cordobesa y, por otra parte, todavía no ha sido estudiado en extensión ningún poblado neolítico de superficie.

En cuanto al calcolítico, este horizonte está peor conocido que en Andalucía oriental y Portugal, con sólo dos poblados excavados, Papaúvas y Cabezo de los Vientos, además de algunos conjuntos megalíticos de la zona de Huelva y del Aljarafe y Aicores sevillanos, con muy escasos estudios faunísticos y carpológicos.

Aunque se observa una evolución del sustrato epipaleolítico, de donde emerge el neolítico, en las estratigrafías, excepto en el Cabezo de Lebrija, Hoyo de la Mina y Nerja, no ha podido captarse la secuencia, pero la 
industria lítica tallada confirma esta evolución de facies microlaminar con muy escaso componente geométrico, con láminas de borde abatido, buriles, perforadores y fracturas.

La antigua nomenclatura de cultura de las cue as aplicada al neolítico antiguo y medio ha caído en desuso, de la misma manera que los apelativos de neolítico hispano-mauritano e ibero-sahariano, propuestas en función de un origen ilusorio actualmente inaceptable. Hoy día es más plausible denominarlo neolítico de la cerámica a la almagra por la constante presencia de este elemento característico en el horizonte antiguo y medio.

Al neolítico medio podría llamársele neolítico de la cerámica incisa por la abundancia de esta técnica, debiéndose desechar la etiqueta de epicardial, al no ser la cerámica cardial característica de nuestro neolítico antiguo.

El neolítico final suele confundirse con el horizonte de transición al calcolítico por la temprana aparición del megalitismo portugués y por la multiplicación de poblados al aire libre, denominándose también neolítico de los silos y de la cerámica lisa.

El calcolítico, dividido a su vez en precampaniforme y campaniforme, como sucede en el resto peninsular, se denomina también eneolítico o edad del cobre, habiéndose desechado definitivamente el nombre de bronce I. Por los dos yacimientos significativos por la antigüedad de sus excavaciones, al calcolítico antiguo se le designa horizonte Millares-Vilanova de San Pedro I, y al calcolítico reciente o campaniforme, Millares-Vilanova II.

En Andalucía occidental se han obtenido las fechas más altas del neolítico antiguo peninsular en los estratos inferiores de las cuevas de la Dehesilla y Santiago Chica de Cazalla, alcanzando desde la primera mitad del vi milenio a mediados del $v$ a.C. El neolítico medio, en esas dos cuevas indicadas y en la de los Murciélagos de Zuheros ha podido fecharse en la segunda mitad del v y primera mitad del Iv milenio a.C. en carbono no calibrado. El neolítico final ha dado una cronología de la segunda mitad del IV milenio y principios del III a.C. El horizonte calcolítico precampaniforme, con extensos poblados y abundante megalitismo funerario admite una cronología del III milenio a.C. con una fecha inicial imprecisa, pero de principios del milenio y una fecha final hacia el 2200 a.C., momento en que pudo ya aparecer el vaso campaniforme, perdurando ampliamente en casi toda la primera mitad del II milenio a.C. e interfiriéndose con un problemático bronce, todavía mal definido. Las fechas radiocarbónicas han creado graves problemas, según hayan sido calibradas o no, advirtiéndose notables diferencias y anacronismos entre ellas de más de medio milenio, con las consiguientes extorsiones. 
Por los datos de que disponemos, todavía insuficientes, el neolítico emergería en una zona nuclear de las sierras de Cádiz y en las estribaciones occidentales de la cordillera Subbética con expansiones hacia las marismas del Guadalquivir, costa malagueña, sierras meridionales de Córdoba y, atravesando el Guadalquivir hacia el norte, hacia Sierra Morena.

Hemos defendido una zona nuclear, de emergencia de un neolítico, en parte autóctono, en las estribaciones de las sierras Subbéticas occidentales, basándonos en hechos tan significativos como las altas fechas radiocarbónicas, el fuerte sustrato epipaleolítico del componente lítico tallado, los fragmentos de cerámica apenas cocida con improntas de cestería del epipaleolítico de Nerja, la abundancia y perfección de la cerámica a la almagra, anterior a la cardial levantina, y la presencia de fauna doméstica en los niveles inferiores.

Con el neolítico medio y final se asiste a un notable incremento poblacional con habitats en cueva y superficie que se extiende sensiblemente por casi toda Andalucía occidental. Esta eclosión demográfica se incrementa en el calcolítico con la emergencia de los grandes poblados repletos de silos, zanjas y cabañas, situados en puntos estratégicos y zonas fértiles de valles y campiñas, dotados, en ocasiones, de extensas necrópolis megalíticas que perduran en el campaniforme.

En la prehistoria occidental quizás se ha abusado del fenómeno de la evolución o emergencia para explicar los ambios socioculturales, abolida la difusión. No obstante parece evidente que el fenómeno de la difusión puede rastrearse, al menos, en algunos elementos, como la cerámica cardial, que, de origen levantino, penetra muy débilmente por el sur de Andalucía occidental en un neolítico antiguo avanzado, interfiriéndose con la especie autóctona a la almagra. La cerámica a la almagra, por otra parte, se difunde, según hemos visto, desde su foco primigenio hacia el Guadalquivir y hacia Andalucia oriental, quizás ya a fines del vı milenio a.C. Los brazaletes de mármol, tanto los lisos del neolítico antiguo, como los estriados del medio, parecen tener su cuna en la costa malagueña, desde donde se expandirian hacia Cádiz, Córdoba y Granada. La agricultura cerealística, documentada, al parecer, en el neolítico antiguo de la cueva de los Mármoles y en el medio de los Murciélagos de Zuheros y del Toro, de origen levantino, no alcanzará la costa malagueña (Nerja) hasta el neolítico final, en las postrimerías del Iv milenio a.C. El fenómeno megalítico, originado probablemente en el neolítico final portugués, parece implantado en Andalucía occidental desde el oeste a principios del III milenio a.C. El vaso campaniforme en sus especies marítimo, Palmela y 
Ciempozuelos, según las últimas investigaciones, deben considerarse como productos de importación, independientemente de su evidente evolución y pervivencias locales en Carmona y los Alcores.

Con estos escasos datos cronológico-culturales y ante los anacronismos creados por el C 14, según haya sido o no calibrado, resulta ilusorio aplicar el modelo de Ammerman y Cavalli-Sforza, denominado de difusión démica o de frente de avance, con grados de medio milenio, al debate difusionismo-evolucionismo de Andalucía occidental.

La cerámica ha servido como elemento característico para identificar los horizontes culturales, de este modo el neolítico antiguo se caracteriza por los inicios de la cerámica a la almagra con decoración acanalada, impresa y plástica, con muy débil presencia de cardial, siempre ausente en Córdoba y norte del Guadalquivir, dotada de variedad de elementos de prehensión. Con el neolítico medio la cerámica a la almagra se expande intensa y ampliamente hacia Córdoba, Sierra Morena y costa meridional, donde alcanza el apogeo, mientras que en la zona nuclear de la Subbética occidental, casi extinguida, es sustituída por las cerámicas incisas y grabadas con barrocos motivos geométricos, acompañados de la técnica cardialoide y plástica. Los elementos de prehensión se diversifican con gran variedad de asas de apéndice, de cinta, de pitorro y multiforadas. En el neolítico final la decoración cerámica pierde entidad, perdurando las series de trazos, estampillados y zig-zags verticales incisos paralelos, iniciándose la técnica pintada. Las formas de los vasos, con tendencia a abrirse, cstentan bordes indicados y perfiles quebrados en $Z$.

Con el calcolítico las cerámicas pierden la decoración, adquiriendo definitivamente formas abiertas, de mayor tamaño, confeccionadas con pastas toscas. La forma característica calcolítica serán los platos, al principio carenados, seguidos por los de borde grueso o almendrado, abundando otras formas semiesféricas, peraltadas, globulares, achatadas, lenticulares, carenadas e incluso teriomorfas y cucharas. Como técnicas decorativas surgen las pastillas repujadas y la pintura.

En el calcolítico final u horizonte campaniforme prosiguen los platos de borde almendrado y en general se asiste a una evolución de las formas cerámicas anteriores. Aparte de la técnica pintada persistente, nace la técnica de la retícula bruñida (Valencina, Cazalla, Alcores, Castro del Río), que un milenio después será la protagonista en el horizonte tartesio del bronce final y orientalizante antiguo. En una fecha imprecisa de fines del III milenio irrumpe desde Portugal y La Meseta el vaso campaniforme en sus diferentes modalidades, estando ausente el tipo primitivo cordado.

La industria lítica tallada, de tradición epipaleolítica, corresponde a la facies microlaminar en el neolítico antiguo con una tipología de raspadores, 
buriles, bordes abatidos y perforadores. En el neolítico medio no se observan grandes cambios aparentes, prosiguiendo la facies anterior microlaminar, pero con débil presencia de geométricos trapezoidales y segmentos. En el neolítico final continúa la evolución de los tallados con tipología de raspadores nucleiformes, laminitas de borde abatido, muescas, fracturas retocadas, láminas de retoque continuo y escasa presencia de geométricos trapezoidales y triangulares. En el calcolítico antiguo hacen acto de presencia los dientes de hoz, láminas denticuladas, crestas, foliáceos o puntas de flecha de base recta o cóncava y la macroindustria sobre lasca o sobre láminas con formas de grandes puñales y alabardas, aumentado los geométricos. Con el campaniforme se diversifican los foliáceos, adquiriendo gran perfección los puñales alabardas y las puntas de flecha de grandes aletas e introduciéndose debilmente los tipos de aletas y pedúnculo, típicas de la parte oriental.

Respecto a la piedra pulimentada, predomina la azuela en el neolítico antiguo, acompañada de hachas y cinceles en el neolítico medio y final. En el calcolítico aumenta el porcentaje de pulimentados con grandes ejemplares diversificados de hachas, azuelas, cinceles y alisadores.

La industria del hueso será abundante desde el neolítico antiguo, representada por punzones fabricados sobre metápodos de ovicápridos, con la punta en bisel y con tipos de media caña, por agujas y espátulas. En el neolítico medio se tiende a la diversificación, apareciendo los punzonesdiente, espátulas y punzones planos con amplia cabeza, punzones de doble punta, enmangues y anzuelos. En el neolítico final todo este repertorio es acompañado por los peines, que prosiguen en el calcolítico.

Entre los elementos de adorno personal destacan los brazaletes de mármol, iniciados primeramente los lisos, cuyos ejemplares más antiguos y abundantes radican en la costa malagueña, desde donde irradiarían en todas las direcciones, traspasando los límites regionales. Los colgantes son elementos esenciales de adorno, destacando en el neolítico antiguo las cuentas de hueso tubulares y las conchas marinas perforadas, muy abundantes en las proximidades de la costa. Con el neolítico medio los anchos brazaletes de mármol estriados, al parecer, también de origen malagueño, junto con los de corona circular de pizarra, atraviesan el Genil, penetrando en el sur de Córdoba. Los colgantes se diversifican con la aparición de dientes perforados, haciendo acto de presencia los anillos de hueso y las plaquitas separadoras de cuentas de collar, que prosiguen en el neolítico final. En el calcolítico se asiste a la proliferación de colgantes y cuentas de diversas piedras raras como la variscita y jadeíta, de hueso y cerámica con formas discoidales, ovales, bitroncocónicas, cilíndricas, 
haciendo su aparición el marfil y las cuentas de huevo de avestruz de indudable procedencia africana. En el horizonte campaniforme el repertorio de adornos aumenta sus tipos con los botones de hueso o marfil con perforación en $\mathrm{V}$ y con las placas perforadas consideradas como brazaletes de arquero.

Los inicios de la metalurgia del cobre parece que no acompaña al momento de la implantación de la sociedad calcolítica. La metalurgia en muy pequeña escala y de tipo doméstico no afectará al cambio socio-económico ya que será en el calcolítico avanzado, hacia mediados del III milenio y en el campaniforme con la producción y generalización de un utillaje metálico variado de hachas planas, cinceles, puñales de lengüeta y agujas cuando incida en el prestigio de las clases más favorecidas. Con el campaniforme la industria metalúrgica del cobre se generaliza definitivamente, documentada por abundantes escorias, crisoles y por un variado utillaje compuesto por cinceles, leznas, punzones, hachas planas, sierras, puntas de flecha tipo Palmela, puñales de lengüeta y con escotaduras laterales. En escasa proporción se usa el oro como elemento de adorno personal.

La economía en el neolítico antiguo y según las zonas sigue un ritmo arcaizante con predominio de la depredación, estando, al parecer, documentada la agricultura cerealística en un silo de la cueva cordobesa de los Mármoles. En el neolítico medio se constata con evidencia en la cueva de los Murciélagos de Zuheros con trigo y cebada y en la cueva malagueña del Toro. Por otra parte, la frecuencia de bellotas, pistachos y olivas no indica necesariamente el cultivo de estas especies. En el neolítico final la agricultura cerealística se ha generalizado, alcanzando la costa malagueña (Nerja) y estando suficientemente constatada por la frecuencia de silos en los poblados que perdurarán en el calcolítico, momento en que se practica una agricultura rotatoria de cereales, con la introducción de nuevas especies vegetales, procediéndose a la explotación sistemática de los terrenos fértiles. No cabe duda del decisivo papel que jugó la agricultura extensiva en la emergencia y eclosión demográfica del calcolítico con la multiplicación de asentamientos en todo el valle del Guadalquivir y en las campiñas cordobesa y sevillana.

La fauna, elemento esencial de la economía, ha sido estudiada en las cuevas neolíticas de la Dehesilla, Parralejo, Santiago Chica de Cazalla y Murciélagos de Zuheros. En el neolítico antiguo la Dehesilla presenta el $75 \%$ de fauna salvaje frente al $25 \%$ de doméstica y en Santiago Chica el $77 \%$ es salvaje. En el neolítico medio de la Dehesilla la fauna doméstica ha alcanzado ya el $80 \%$. En el neolítico final la Dehesilla presenta el $90 \%$ de doméstica y en Santiago Chica se equiparan ambos tipos, 
dependiendo estos porcentajes del medio ambiente y del carácter temporal del habitat. Con el calcolítico vuelve a aumentar la caza en las cuevas, como asentamientos temporales, mientras que en los grandes poblados de llano el predominio de la fauna doméstica es absoluto, llegando en Papaúvas al $90 \%$.

El tejido de lana y lino aunque pudo iniciarse en el neolítico final, se industrializa en el calcolítico, estando abundantemente documentada por las placas de cerámica con los extremos perforados o pesas de telar.

Los ritos funerarios se documentan en el neolítico de las cuevas de habitación, siendo un buen ejemplo la Dehesilla donde en el neolítico aniguo y medio se localizaron varios enterramientos individuales y colectivos con los cadáveres encogidos, en decúbito lateral con el cráneo manchado de ocre, sin ajuar aparente y protegidos por piedras y con ciertos indicios de cremación parcial. En ocasiones en el neolítico antiguo y medio se utilizan galerías estrechas y simas para el enterramiento con ajuares cerámicos, como sucede en la zona de Benaocaz (Cádiz). En el neolítico final se inician las primeras sepulturas, preludio del megalitismo, con tumbas de grandes bloques o fosas con enterramientos individuales o dobles con pobres ajuares, estudiadas en San José del Valle (Cádiz). Con el calcolítico, independientemente de los enterramientos tradicionales en cueva, se asiste a un rotundo cambio en las prácticas funerarias con la aparición del enterramiento colectivo de carácter megalítico, que invadirá toda la región y cuyo origen parece portugués del Alto Alentejo. La tipología de estos grandes monumentos funerarios es sumamente variada con formas de dolmen simple, galería cubierta, sepulcro de corredor y tholos o sepulcro de falsa cúpula, incluyéndose la cueva artificial.

El dolmen simple es quizás el primero en aparecer, probablemente en el momento de transición, por Sierra Morena y Sierra de Cádiz. La galería cubierta, extendida por Sierra Morena y río Odiel con penetración hacia el este, correspondería a la fase inicial. El dolmen de corredor con diferentes variantes se extiende por la Sierra de Huelva con extensiones por la Sierra Morena central, el Guadalquivir y la Subbética occidental. El tholos, distribuído por todo el territorio, prefiere los grandes llanos, siendo problemático su origen en alguno de los tres grandes focos, bajo Guadalquivir, Tajo - Almería y caracterizándose por la riqueza y abundancia de ajuares de un momento avanzado. La cueva artificial, de tipo furniforme, como réplica del tholos, o siliforme, se extiende por las campiñas y sur de Cádiz, llegando las más tardías al horizonte campaniforme e incluso al bronce. Muchos de estos monumentos están cubiertos por túmulo o incrustados en 
pequeñas elevaciones del terreno. Sus abundantes ajuares sumamente variados han proporcionado la mayor parte del registro para el estudio del calcolítico.

No cabe duda de que el arte rupestre esquemático se inicia ya en el neolítico antiguo o antes, correspondiendo a este momento las formas seminaturalistas de los abrigos del Campo de Gibraltar. El arte esquemático propiamente dicho se generaliza en el neolítico medio, prosiguiendo hasta un calcolítico avanzado del campaniforme, extendido por toda la Sierra Morena y las sierras del sur de Córdoba. Con el calcolítico el componente principal sería de caracter simbólico con representaciones de pectiniformes, zig-zags, esteliformes y trazos inconexos, prosiguiendo los esquematismos con ejemplos de grabados en dólmenes, de interés por su posibilidad de datación.

El habitat, generalmente en cueva en el neolítico antiguo y medio, adopta igualmente el poblado de superficie, cuya detección se hace difícil por la erosión y acumulación de depósitos, como en los Pozos de Lebrija. En el neolítico medio el habitat de superficie gana terreno con la ocupación de valles y marismas del Guadalquivir, Cádiz y Huelva (Lucena del Puerto, El Judío, Chipiona, Lebrija, Prado del Rey, El Yugo), presentándose como conjuntos de cabañas de planta circular con zócalos de piedra. Con el neolítico final surgen las bases de los grandes poblados calcolíticos dotados de cabañas circulares, silos, fosos y trincheras. Con el calcolítico el habitat característico es el poblado de superficie, habiendo sido localizados en abundancia en el sur de Córdoba, Alcores, Aljarafe, Cádiz, Huelva y Málaga. Estos asentamientos prefieren zonas fértiles y estratégicas junto a ríos y marismas, emplazados en pequeñas alturas y ocupando superficies que alcanzan las diez hectáreas."Estos poblados carecen de defensas artificiales, excepto del Cabezo de los Vientos (Huelva) que dispone de murallas y torres circulares.

En los diferentes horizontes del neolítico y calcolítico han podido delimitarse mediante las estratigrafías algunos estadios. En el neolítico antiguo, medio y final se han establecido subfases A y $B$ en las estratigrafías de las cuevas de la Dehesilla, Parralejo, Santiago Chica y en el poblado del Cabezo de Lebrija. En el neolítico final y calcolítico de Papaúvas se ha conseguido una estratigrafía horizontal de cuatro fases.

Las facies regionales del neolítico y calcolítico de Andalucía occidental en líneas generales se acomodan sensiblemente a la repartición geográfica delimitada al principio de este estudio, manteniendo unas constantes a través de toda la prehistoria. 


\section{BIBLIOGRAFÍA}

Acosta, P., 1968: La pintura rupestre esquemática en España. Salamanca.

Acosta, P., 1986: El neolítico en Andalucía Occidental. Estado actual. Homenaje a L. Siret. Madrid, 136-151.

Acosta, P., Pellicer, M., 1990: Las primeras civilizaciones prehistóricas en Andalucía Occidental. La Cueva de la Dehesilla (Jerez de la Frontera), Inst. Estudios Jerezanos. Jerez.

Aguado, T. y Baldomero, A., 1979: Estudio de los materiales de superficie de la Cueva de las Palomas (Teba, Málaga). Mainake I, Málaga, 29-59.

Almagro Gorbea, Ma Josefa, 1973: Los idolos del Bronce / Hispano. Bibl. Praeh. Hisp. XIl, Madrid.

AMmERMAN, A.J. y CAVALLi-SForza, L.L., 1973: A population model for the difusion of early farming in Europe. Renfrew Edit., 343-358.

Asquerino, Ma D., 1987: Cueva de los Mármoles. En. Arq. Andalucía 1986. 1, 31.

BERDICHEWSKY, B., 1964: Los enterramientos en cuevas artificiales del Bronce / Hispánico. Bibl. Praeh. Hisp, VI. Madrid.

Blance, B., 1971: Die Anfänge der Metallurgie auf der Jberischen Halbinsel S.A.M., 4, Berlin.

BOESSNECK, J. und VON DER DRIESCH, A., 1980: Tierknochenfunde aus vier südspanischen Höhlen. Studien über Frühe Tierknochenfunde von der lberischen Halbinsel. 7. München, 20-81.

BonsoR, G., 1899: Les colonies agricoles pré-romaines de la Vallée du Betis. Revue Archéol., 35, París.

Bosch, P., 1954: La cultura de las cuevas en Africa y en España y sus relaciones. I congr. Arq. Marruecos Esp. Tetuán.

BUBNER, 1981: Endneolithikum und Frünbronzezeit im untere Guadalquivirbechen. Zephyrus XXXII-XXXIII, Salamanca, 133-135.

CABRE, J. y HERNÁNDEZ, E., 1914: Avance al estudio de las pinturas prehistoricas del Extremo Sur de España (Laguna de la Janda). Com. Inv. Paleont. y Preh. Memoria 3. Madrid.

Cabrero, R., 1988: El conjunto calcolítico de los Delgados, Fuenteobejuna (Córdoba). Córdoba.

Carbonell, A., 1925: Los hallazgos prehistóricos de Jabugo. Bol. Real Acad. C. Bell. Artes de Córdoba, 11. Córdoba, 57 y ss.

CARO, A., 1982: Notas sobre el calcolítico y el bronce en el borde de las marismas de la margen izquierda del Guadalquivir. Gades 9. Cádiz, 71-91.

CARO A. y otros, 1987: Informe sobre la prospección arqueológica con sondeo estratigráfico en el solar de la calle Alcazaba (Lebrija, Sevilla). An Arq. Andalucía (1986), II, Sevilla, 168-174.

Carriazo, J.M., 1961: El Dolmen de Ontiveros. Homenaje al Prof. C. de Mergelina. Murcia, 1-21.

CARRILERO, M. y otros, 1982: El yacimiento de Morales (Castro del Río, Córdoba): La cultura de los silos en Andalucia Occidental. Cuad. Preh. Univ. Granada, 7, 171-188.

CASTILLO A. DEL, 1928: La cultura del vaso campaniforme. Barcelona.

CERdÁn, C. y LeISNER, G. y V., 1952: Los sepuicros megalíticos de Huelva. Com. Gral. Exc. Arq. Informes y Mem, 26, Madrid.

Collantes de Teran, F., 1969: El dolmen de Matarrubilla. V Simp. Intern. Preh. Pen. Barcelona, $47-62$.

CRuz-Auñon, R. y JimÉnez, J.C., 1986: Historia crítica del antiguo yacimiento de Campo Real (Carmona), Habis 16, Sevilla, 417-452.

Cruz-Auñon, R. y Rivero, E., 1987: Gilena, un foco de especial interés para el estudio de la edad del cobre en Andalucia. Sevilla.

Escacena, J.L., 1987: Excavaciones en la Marismilla (Puebla del Río, Sevilla). An. Arq. Andalucia (1985), IIl, Sevilla, 296-298.

EscacenA, J.L. y otros, 1984: Avance al estudio del yacimiento del Cerro del Berrueco (Medinasidonia, Cádiz). Anales Univ. Cádiz 7-32.

Fernández, F. y Ruiz, D., 1978: El "tholos" del Cerro de la Cabeza en Valencina de fa Concepción (Sevilla). Trab. Preh., 35, Madrid, 193-224.

Ferrer, J., 1987: El megalitismo en Andalucía Central. En El Megalitismo en la Península Ibérica. Madrid, 9-29.

FERRER, J, y MARQUÉs, I., 1986: El cobre y el bronce en tierras malagueñas. Hom. a $L$. Siret. Madrid, 251-261.

FORTEA, J., 1973: Los complejos microlaminares y geométricos del epipaleolítico mediterráneo español. Salamanca. 
Gavilian, B., 1987: El neolítico del sur de Córdoba. Córdoba.

GueRRERO, L.J., 1982: Avance sobre algunos descubrimientos neolíticos en la Sierra de Cádiz. Hom. a C. Fernandez. Madrid, 55-68.

HARRISON, R.J., 1977: The Bell Beaker of Spain and Portugal. Cambridge-Massachusetts.

HARRISON, R., BuBner, T. y HiBBS, V., 1976: The beaker pottery from El Acebuchal, Carmona (prov. Sevilla). Madr. Mitt., 17.

Hopf, M., 1974: Breve informe sobre el cereal neolítico de la Cueva de Zuheros. Trab. Preh. 31, Madrid, 295-296.

Hopf, M. y Pellicer, M., 1970: Neolithische Getrejdefunde in der Höhle von Nerja (prov. Málaga). Madr. Mitt. 11, 18 y sig.

Hopf, M. y MuÑoz, A.M., 1974: Neolithische Pflanzenreste aus der Höhle Los Murciélagos bei Zuheros, prov. Córdoba. Madr. Mitt. 15, 9-27.

LEISNER, G. und V., 1943: Die Megalithgräber der Iberischen Halbinsel. 1) Der Süden. RömGerm. Forsch. 17, Berlin.

LÓPEZ, P. y CACHO, C., 1978: La problemática cronológica del neolítico peninsular. Reunión Fund. March, Serv. Univ. 77, Madrid, 11 y sig.

LóPEZ, P. y CACHO, C., 1979: La cueva del Higueron (Málaga). Estudio de los materiales. Trab. Preh. 36, Madrid, 11-81.

Martín de LA Cruz, J.C., 1985: Papaúvas I. Exc. Arq. España 136, Madrid.

Martin de La Gruz, J.C., 1986: Papaúvas II, Aljaraque, Huelva. Exc. Arq. España, 149, Madrid.

MARTIN DE LA CRUz, J.C., 1994: El tránsito del neolítico al calcolítico en el litoral del suroeste peninsular. Exc. Arq. España, 169. Madrid.

MARTín, D. y otros, 1987: Informe preliminar de la campaña de 1985 en la Cueva del Toro de El Torcal (Antequera, Málaga). An. Arq. Andalucía (1985), II, Sevilla, 233-240.

MARTínez, R. y PeredA, C., 1990: La necrópolis prehistórica del Cerro de la Casería, Alcalá del Valle (Cádiz). An. Arq. Andalucía (1988), III, Sevilla, 78-83.

Muñoz, A.M ${ }^{\sharp}$, 1970: Estado actual de la investigación sobre el neolítico español. Pyrenae VI, Barcelona, 13-28.

MuÑoz, A.M $M^{a}$ 1975: Consideraciones sobre el neolitico español. Instituto de Arqueología de la Universidad de Barcelona.

MURILLO, J.F., 1990: Estado de la cuestión sobre el problamiento durante el calcolítico y edad del bronce en las Subbéticas cordobesas. Anales Arqueología Cordobesa, I, Córdoba, 53-81.

NAVARRETE, Ma S., 1976: La cultura de las cuevas con cerámica decorada en Andalucía Oriental. 2 vols. Universidad de Granada.

NAvarRo, E.J., 1984: Estudio prehistórico sobre la Cueva del Tesoro. Málaga.

OLARIA, C., 1977: Las cuevas de los Botijos y de la Zorrera en Benalmádena. Benalmádena.

OLARIA, C., 1986: La problemática del neolítico andaluz y sus conexiones con el litoral mediterráneo peninsular. Hom. a L. Siret. 130-135.

Pellicer, M., 1963: Estratigrafía prehistórica de la Cueva de Nerja (Málaga) Exc. Arq. España, 16, Madrid.

Pellicer, M., 1986: El cobre y el bronce pleno en Andalucía Occidental. Hom. a L. Siret. Barcelona, 245-250.

Pellicer, M., 1986: Neolítico. Prehistoria de España, 1, Edit. Gredos, Madrid, 151-206.

Pellicer, M. y Acosta, P., 1982: El neolítico antiguo en Andalucía Occidental. Coll. Int. Preh. Montpellier, 1981, 49-60.

Pellicer, M. y Acosta, P., 1986: Neolítico y calcolítico de la Cueva de Nerja. Trab. Cueva de Nerja. Málaga, 339-450.

Perdigones, L. y otros, 1987: Excavaciones de urgencia en la Base Naval de Rota (Puerto de Santa María, Cádiz). An. Arq. Andalucía (1985), III, Sevilla, 74-80.

PIÑón, F., 1987: Constructores de sepulcros negalíticos en Huelva: Problemas de una implantación. El Megalítismo en la Península lbérica, Madrid, 45-72.

Piñón, F., 1987: El Cabezo de los Vientos, La Zarcita (Santa Bárbara de Casa): An. Arq. Andalucía (1985), Il. Sevilla, 272-278.

Posac, C., 1975: Los Algarbes (Tarifa) Una necrópolis de la edad del bronce. Not. Arq. Hisp., Preh. 4, Madrid, 87 y sig.

RAMOS, J. y MARTín, E., 1987: Tajo Gomer (Riogordo, Málaga): Un asentamiento neolítico al aire libre en el Alto Vélez. Vélez Málaga. 
RIVERO, E., 1988: Análisis de las cuevas artificiales en Andalucia y Portugal. Sevilla.

Rubio, I., 1974: Bases para el estudio de la economía agrícola y ganadera en el neolítico hispano. C.P.A.U.A.M.1, Madrid, 9 y sig.

San Valero, J., 1975: Los hallazgos antiguos del neolítico de Gibraltar. Pap. Lab. Arq. Univ. Valencia, 11, 75-108.

SERNA, M.R., 1989: El vaso campaniforme en el valle del Guadalquivir. Tartessos. Barcelona, 4784.

SuCH, M., 1919: Avance al estudio de la caverna de Hoyo de la Mina. Bol. Soc. Mal. de Ciencias. Málaga.

Vallespl, E. y Cabrero, R., 1980-81: Calcolítico y bronce pleno en el Moral de Montecorto, Ronda. Mainake II-III, Málaga, 48-63.

VICENT, A. Mª y Muñoz, A. Ma, 1973: La Cueva de los Murciélagos de Zuheros (Córdoba). Exc. Arq. España, 77. Madrid. 